\title{
Private investment and financial development in a globalized world
}

\author{
Yongfu Huang
}

Discussion Paper No. 06/589

July 2006

Department of Economics

University of Bristol

8 Woodland Road

Bristol BS8 1TN 


\title{
Private investment and financial development in a globalized world ${ }^{*}$
}

\author{
Yongfu Huang ${ }^{\dagger}$ \\ Department of Economics, University of Bristol \\ 8 Woodland Road, Bristol BS8 1TN
}

July 8, 2006

\begin{abstract}
Using recently developed panel data techniques on data for 43 developing countries over the period 1970-98, this paper provides an exhaustive analysis of causality between aggregate private investment and financial development. GMM estimation on averaged data, and a common factor approach on annual data allowing for global interdependence and heterogeneity across countries suggest positive causal effects going in both directions. The finding has rich implications for the development of financial markets and the conduct of macroeconomic policies in developing countries in an integrated global economy.

Keywords: Private Investment; Financial Development; Global Interdependence; Common Factor Analysis; Panel Unit Root Test; Panel Cointegration Test
\end{abstract}

JEL Classification: F36; F41; E22; E44

*I am very grateful to Jonathan Temple for his valuable supervision, comments and assistance throughout the preparation of this paper. The usual disclaimer applies.

${ }^{\dagger}$ Correspondence: Email: y.huang@bristol.ac.uk; Tel: 0044-117-928 8402; Fax: 0044117-928 8577 


\section{Introduction}

In recent decades there has been a large body of literature studying the substantial roles investment and financial development play in long-run economic growth (Levine and Renelt 1992; King and Levine 1993 among others). This paper aims to provide an exhaustive analysis of the existence and directions of causality between these two important aspects of economic activities, namely aggregate private investment and financial development. By exploiting the time series variation in both private investment and financial development, and allowing for global interdependence and heterogeneity across countries, this paper suggests positive causal effects going in both directions.

As is well-known, in the absence of asymmetric information, financial markets can function efficiently in the sense that, for any investment project, the financial contract provides the borrowers and investors with expected payments determined by the prevailing economy-wide interest rate. However, entrepreneurs in reality are always much better informed than investors as to the outcome of investment projects and their actions, calling for costly state verification conducted by financial intermediaries (Townsend, 1979) ${ }^{1}$, and the corresponding contracting problem between financial intermediaries and entrepreneurs (Diamond 1984; Gale and Hellwig 1985; Williamson 1986, 1987 and Bernanke and Gertler 1989). Does entrepreneurs' investment behaviour exert any effect on the expansion of financial system or the reduction of agency costs? Does the increase of private investment as a whole contribute to financial development? On the other hand, another natural question could be whether more efficient financial markets encourage entrepreneurs' investment behaviour, or whether financial development brings about a surge of private investment.

Economic theory in general predicts that private investment and financial intermediary development contribute in a significant way to each other. On the one hand, an increase in private investment constitutes rising demand for

\footnotetext{
${ }^{1}$ Financial intermediaries emerge endogenously under certain conditions, as widely addressed by Diamond (1984) and Williamson (1986), to avoid the duplication of monitoring costs (to minimise the monitoring costs by pooling projects), to channel savings from households to firms for use in the production process and to pool risk.
} 
external finance, enlarging the extent of financial intermediation by directly encouraging financial intermediaries to persuade savers to switch their holdings of unproductive tangible assets to bank deposits. Levine and Renelt (1992) suggest that more investment raises the rate of economic growth, which could stimulate financial development (Greenwood and Smith, 1997). On the other hand, the endogenous finance-growth models (for example Diamond 1984; Diamond and Dybvig 1984; Greenwood and Jovanovic 1990; Bencivenga and Smith 1991; Greenwood and Smith 1997) suggest that financial markets have an important role in channelling investment capital to its highest valued use. Financial intermediaries tend to induce a portfolio allocation in favor of productive investment by offering liquidity to savers, easing liquidity risks, reducing resource mobilization costs and exerting corporate control. It seems natural to wonder if what is possible in theory is consistent with what has happened in reality.

The causes of financial development have become an increasingly significant research area in recent years ${ }^{2}$. Following the renowned Solow-Swan growth model, much research has been undertaken to examine the long-run determinants of economic growth. Levine and Renelt (1992) emphasize the critical role of investment in growth, leading to investment being included in most growth regressions. However, there has been little work on the role of investment in the determination of financial development.

Much work has been done to investigate the determinants of investment since the $1990 \mathrm{~s}^{3}$. Following the influential work by King and Levine (1993)

\footnotetext{
${ }^{2}$ Among others, Huang (2005a) examines the long-run determinants of financial development by using Bayesian Model Averaging and General-to-specific approaches. That paper suggests that "the level of financial development in a country is determined by its institutional quality, macroeconomic policies, and geographic characteristics, as well as the level of income and cultural characteristics". Huang (2005b) reveals that political liberalization is typically followed by a higher level of financial development at least in the short-run. Huang and Temple (2005) find a positive effect of increases in goods market openness on financial development.

${ }^{3}$ Among others, Doms and Dunne (1993) show that microeconomic lumpiness is very important for aggregate investment. Bertola and Caballero (1994) argue that microeconomic irreversibilities play an important role in smoothing investment dynamics in the presence of idiosyncratic uncertainty. In the industrial orgainzation literature, Dixit (1989), Leahy (1993) and Caballero and Pindyck (1996) discuss the consequences of the entry (creation) decision of new (incumbent) enterpreneurs and exit decisions of some incumbents for variation in the aggregate stock of capital.
} 
who find a positive effect of financial development on various aspects of economic activity, several empirical studies provide evidence in support of a positive impact of financial development on capital formation in the private sector ${ }^{4}$. However, existing research in general assumes error independence across countries, which is a highly restrictive assumption to make, particularly in the context of globalization.

This background has motivated research into the interactions between aggregate private investment and financial development in this paper. The econometric analysis is based on a dataset for 43 developing countries over the period 1970-98. Since commercial banks dominate the financial sector and stock markets play very minor roles in most developing countries, this research focuses on the level of financial intermediary development, for which a new index is constructed by using principal component analysis based on three banking development indicators ${ }^{5}$ widely used in the literature. This research has become more important as many developing countries have sought to stimulate economic growth by choosing to encourage private investment, while abandoning import-substitution policies led by the public sector, since the 1970s.

It is worth noting that this analysis focuses on the period when, after the collapse of the Bretton Woods system, the world economy has experienced "a new and deeper version of globalization" following "a gradual liberalization of trade and capital flows" (Crafts, 2000). The increase in global trade and financial integration ${ }^{6}$ has been found to induce closer interdependence in the global economy through its implications for the properties of business cycle fluctuations. Imbs (2003) finds, using data for a group of developed and developing countries over 1983-98, that the intensity of financial linkages

\footnotetext{
${ }^{4}$ Benhabib and Spiegel (2000) show that financial development positively influences the investment rate. Schich and Pelgrin (2002) indicate a positive effect going from financial development to private investment in 19 OECD countries over 1970 to 1997. Ndikumana (2000, 2005) finds that the development of banks and stock markets tends to stimulate domestic investment.

${ }^{5}$ Details on these indicators can be found in Section 2.

${ }^{6}$ Kose, Prasad and Terrones (2003) show that the overall volume of international trade and gross private capital flows has increased dramatically over the past three decades, in particular, "the growth of world trade has been larger than that of world income in almost all years since $1970 "$.
} 
and the volume of intra-industry trade have a positive impact on crosscountry business cycle comovement. Frankel and Rose (1998) show that trade partners have a higher degree of business cycle comovement. Kim et al. (2003) observe a high degree of business cycle comovement for a set of Asian emerging market countries over 1960-96.

The phenomenon of business cycle comovement has often been explained by using a common factor analysis in which macroeconomic variables such as aggregate output, consumption and investment are decomposed into common observed global shocks (like sharp fluctuations of oil prices), common unobserved global shocks (like technological shocks), specific regional shocks and country shocks (Gregory et al. 1997; Kose, Otrok and Whiteman 2003; Bai and Ng 2004). It is these shocks that lead to a closer real and financial interdependence across countries.

The 1990s witnessed growing research on the stochastic properties of panel data sets where the time dimension and cross section dimension are relatively large, and especially, the issue of cross section error dependence has received a great deal of attention in recent years. The application of unit root and cointegration tests to panels is motivated by the possible increase of statistical power through pooling information across units. However, the power of tests is increased only when the cross section units are independent, which is an assumption that may be hard to justify given the rising degree of financial market integration and business cycle synchronization. This research attempts to explore this issue by fully taking into account the effects of global shocks causing cross section dependence across countries.

The analysis in this paper includes two steps. The first step is an analysis on data for 5-year averages, which is commonly used in the literature. It applies the system GMM estimation method due to Arellano and Bover (1995) and Blundell and Bond (1998) allowing for possible correlations between regressors and both individual effects and global shocks. It then moves on to the second step, an analysis using methods on pooled annual data assuming a common factor structure in the error term due to Bai and Ng (2004). Before proceeding to estimation, the time series properties of the panel data set are carefully examined. The so-called "second-generation tests" are applied, which allow for cross section dependence, including a panel unit root 
test of Bai and Ng (2004) and a panel cointegration test of Pedroni (2004) on defactored data. The models are then estimated by the Pesaran (2006a) Common Correlated Effect approach.

The analysis on averaged data produces significant findings of positive causal effects going in both directions, and indicates a high degree of persistence exists in the averaged data of financial development and private investment. The annual data study suggests that the series of both private investment and financial development are integrated, and two-way positive long-run causal effects exist in the cointegrated system. The findings of this paper support the view that a private investment boom is typically followed by further financial development, while the demand for external finance is reflected in the subsequent level of financial development. It has significant policy implications for the development of financial markets and the conduct of macroeconomic policies in developing countries in a global economy.

The remainder of the paper proceeds in section 2 to describe the data. Section 3 analyzes this link using system GMM estimation on data for 5-year averages. Section 4 employs the common factor approach to examine this link with annual data, including panel unit root testing, panel cointegration testing, and estimation. Section 5 concludes.

\section{The Data}

This section outlines the measures and data for private investment and financial development. Appendix Table 1 summarizes the variable description and sources.

The measure of private investment, denoted by PI, is the ratio of nominal private investment to nominal GDP. The data are taken from the World Bank Global Development Network Database (2002).

The measure of financial development, denoted by FD, is a new aggregate index constructed by using principal component analysis. Since there is no single aggregate index for financial development in the literature, a principal component analysis is applied for this purpose.

Essentially the principal component analysis takes $N$ specific indicators and produces new indices (the principal components) $\mathrm{X}_{1}, \mathrm{X}_{2}, \ldots \mathrm{X}_{N}$ that are 
mutually uncorrelated. Each principal component, a linear combination of the $N$ indicators, captures a different dimension of the data. Typically the variances of several of the principal components are low enough to be negligible, and hence the majority of the variation in the data will then be captured by a small number of indices.

The principal component analysis is based on the following three popular banking development indicators ${ }^{7}$ :

The first measure, Liquid Liabilities (LLY), is one of the major indicators used to measure the size, relative to the economy, of financial intermediaries including three types of financial institutions: the central bank, deposit money banks and other financial institutions. It is calculated by the ratio of liquid liabilities of banks and non-bank financial intermediaries (currency plus demand and interest-bearing liabilities) over GDP.

The second indicator, Private Credit (PRIVO), is defined as credit issued to the private sector by banks and other financial intermediaries divided by GDP. This excludes the credit issued to government, government agencies and public enterprises, as well as the credit issued by the monetary authority and development banks. It is a general indicator of financial intermediary activities provided to the private sector.

The third one, Commercial-Central Bank (BTOT), is the ratio of commercial bank assets to the sum of commercial bank and central bank assets. It reflects the advantage of financial intermediaries in dealing with lending, monitoring, and mobilizing saving and facilitating risk management relative to the central bank.

Data on these financial development indicators are obtained from the World Bank's Financial Structure and Economic Development Database (2005). FD is the first principal component of these three indicators above and accounts for $74 \%$ of their variation. The weights resulting from principal component analysis over the period 1990-98 are 0.60 for Liquid Liabilities, 0.63 for Private Credit and 0.49 for Commercial-Central Bank. Since these indicators are used to measure the size of financial intermediary develop-

\footnotetext{
${ }^{7}$ The summary below is heavily drawn from Demirgüç-Kunt and Levine $(1996,1999)$. Since the data for stock market development and bond market development are largely incomplete, this research focuses on financial intermediary development.
} 
ment $^{8}$, the composite index, FD, mainly captures the depth of bank-based intermediation.

The panel dataset contains 43 developing countries over the period 197098. The countries in the full sample are listed in Appendix Table 3. The transition economies are omitted. We also exclude countries with less than 20 observations over 1970-98.

Appendix Table 2 presents descriptive statistics for private investment, the measure of financial development, real GDP and trade openness.

\section{Analysis on data for five-year averages}

To examine the relationship between private investment and financial development, this paper conducts panel data estimation for 43 developing countries over 1970-98, based on averaged data over non-overlapping, five-year periods in this section, and annual data in the next section. Panel data estimation tends to produce more convincing findings than cross section analysis and classical time series analysis since it exploits both the cross section and time dimensions of the data. ${ }^{9}$ It allows us to control for unobserved countryspecific effects and omitted variables bias, and look at both long-run effects and short-run effects.

This section mainly focuses on the system GMM method proposed by Arellano and Bover (1995) and Blundell and Bond (1998), using averaged data (with a maximum of 6 observations per country). As widely used in the growth literature (Islam 1995; Caselli et al. 1996; Levine et al. 2000), averaging data over fixed intervals has the potential for eliminating business cycle fluctuations and makes it easier to capture the relationships of interest. Section 3.1 briefly describes the system GMM approach, and section 3.2

\footnotetext{
${ }^{8}$ Two measures for the efficiency of financial intermediation widely used are Overhead Costs, the ratio of overhead costs to total bank assets, and Net Interest Margin, the difference between bank interest income and interest expenses, divided by total assets. Due to the incompleteness of the available data, they are not included in this analysis.

${ }^{9}$ In the growth and convergence context, both the panel data analysis of Caselli et al. (1996) and the cross section analysis of Mankiw et al. (1992) find a negative effect of initial income on growth, but the former identifies a much larger effect than the latter, implying a 10 per cent covergence rate relative to 2-3 per cent suggested by Mankiw et al. (1992).
} 
presents the empirical results.

\subsection{Methodology: System GMM}

The following AR(1) model has been found appropriate for this application $^{10}$ :

$$
\begin{aligned}
\mathbf{F D}_{i t} & =\alpha_{11} \mathbf{F D}_{i, t-1}+\mathbf{P I}_{i, t-1} \beta_{11}+\eta_{i 1}+\phi_{1 t}+v_{i t 1} \\
\mathbf{P I}_{i t} & =\alpha_{12} \mathbf{P} \mathbf{I}_{i, t-1}+\mathbf{F D}_{i, t-1} \beta_{12}+\eta_{i 2}+\phi_{2 t}+v_{i t 2} \\
i & =1,2, \ldots, 43 \text { and } t=2, \ldots, 6
\end{aligned}
$$

For the sake of convenience, denote by $y$ the dependent variable (either FD or PI) and by $x$ the explanatory variables other than the lagged dependent variable:

$$
\begin{aligned}
y_{i t} & =\alpha y_{i, t-1}+x_{i, t-1}^{\prime} \beta+\eta_{i}+\phi_{t}+v_{i t} \\
i & =1,2, \ldots, 43 \text { and } t=2, \ldots, 6
\end{aligned}
$$

where $\eta_{i}$ is an unobserved country-specific time-invariant effect not captured by $x_{i, t-1}$, and can be regarded as capturing the combined effects of all timeinvariant omitted variables.

$\phi_{t}$ captures the global shocks. Recently a large body of literature has indicated that the existence of common factors, either global, cyclical or seasonal effects, has the potential for causing comovements of variables in the world economy. Since common factors are likely to be partially cancelled out when the data are averaged, for simplicity this section only considers common time effects or a single global shock having an identical effect on each cross section unit. The next section explores the effects of common factors in more depth.

\footnotetext{
${ }^{10}$ Starting from a general model with three lags of the dependent and independent variables and testing the null hypothesis of the coefficients being zero for the longest lag, we end up with one lagged independent variable and one lagged dependent variable appearing in the model for this context, given that the relevant specification tests are satisfied.
} 
$v_{i t}$ is the transitory disturbance term, assumed to satisfy sequential moment conditions of the form

$$
E\left(v_{i t} \mid y_{i}^{t-1}, x_{i}^{t-1}, \eta_{i}, \phi_{t}\right)=0
$$

where $y_{i}^{t-1}=\left(y_{i 1}, y_{i 2} \ldots, y_{i, t-1}\right), x_{i}^{t-1}=\left(x_{i 1}, x_{i 2} \ldots, x_{i, t-1}\right)$.

This assumption implies that (1) the transient errors are serially uncorrelated; (2) xs are predetermined variables with respect to the time varying errors in the sense that $x_{i, t-1}$ may be correlated with $v_{i, t-1}$ and earlier shocks, but is uncorrelated with $v_{i t}$ and subsequent shocks; (3) the individual effects are uncorrelated with the idiosyncratic shocks, but correlations between individual effects and lagged $y$ and lagged $x$ are not ruled out; (4) the global shocks are uncorrelated with the idiosyncratic shocks, while correlations between global shocks and lagged $y$ and lagged $x$ are possible.

The assumption on the explanatory variables $x s$ being predetermined rules out a potential endogeneity bias, but allows for feedbacks from the past realizations of $y$ to current $x s$. This assumption is believed to be appropriate given financial deveopment is potentially both a consequence and origin of private investment, and vice versa ${ }^{11}$.

For the stability of the estimated model, the autoregressive coefficient is assumed to lie inside the unit circle, $|\alpha|<1$.

The coefficient $\beta$ reflects the existence and direction of Granger causality going from lagged $x$ to $y$. According to work by Chamberlain (1984) and Holtz-Eakin et al. (1988) on Granger non-causality tests in the general setting of dynamic panel data estimation, the noncausality hypothesis can be tested by checking whether the coefficients of the lagged values of the independent variables are zero or the coefficients on the lagged difference of independent variables in the transformed equations are zero, that is $\beta=0$. Given the model is stable, a point estimate for the long-run effect can be calculated as follows:

$$
\beta_{L R}=\frac{\beta}{(1-\alpha)}
$$

\footnotetext{
${ }^{11}$ Caselli et al. (1996) treat some variables like the investment rate and population growth rate as predetermined and argue that these variables are potentially both causes and effects of economic growth.
} 
The standard error for the long-run effect can be approximated by using the delta method (for example Papke and Wooldridge, 2005).

This analysis employs the system GMM method, which is proposed by Arellano and Bover (1995) and Blundell and Bond (1998) to improve upon the Arellano and Bond (1991) first-differenced GMM method, which may be plagued with weak instrument problems. There have been a number of methods proposed to estimate dynamic panel data models with a short time dimension, in which first-differencing is used to eliminate the individual effects. Below is Equation (3) in first differences:

$$
\begin{aligned}
\Delta y_{i t} & =\alpha \Delta y_{i, t-1}+\Delta x_{i, t-1}^{\prime} \beta+\Delta \phi_{t}+\Delta v_{i t} \\
i & =1,2, \ldots, 43 \text { and } t=3, \ldots, 6
\end{aligned}
$$

where $\Delta y_{i t}=y_{i t}-y_{i, t-1}, \Delta x_{i, t-1}=x_{i, t-1}-x_{i, t-2}, \Delta \phi_{t}=\phi_{t}-\phi_{t-1}$ and $\Delta v_{i t}=v_{i t}-v_{i, t-1}$.

The sequential moment conditions above imply that all lagged values of $y_{i t}$ and $x_{i t}$ dated from $t-2$ and earlier are suitable instruments for the differenced values of the original regressors, $\Delta y_{i, t-1}$ and $\Delta x_{i, t-1}$. While the first-differenced 2SLS estimator due to Anderson and Hsiao (1981, 1982) uses $y_{i t-2}$ and $x_{i t-2}$, the first-differenced GMM estimator uses all lagged values of $y_{i t}$ and $x_{i t}$ dated from $t-2$ and earlier. The moment conditions for errors in differences on which the first-differenced GMM estimator is based can be written as,

$$
\begin{aligned}
E\left[\left(\begin{array}{c}
y_{i}^{t-2} \\
x_{i}^{t-2}
\end{array}\right)\left(\Delta y_{i t}-\alpha \Delta y_{i, t-1}-\Delta x_{i, t-1}^{\prime} \beta-\Delta \phi_{t}\right)\right] & =0 \\
t & =3, . ., 6
\end{aligned}
$$

where $y_{i}^{t-2}=\left(y_{i 1}, y_{i 2} \ldots, y_{i, t-2}\right)$, and $x_{i}^{t-2}=\left(x_{i 1}, x_{i 2} \ldots, x_{i, t-2}\right)$.

Blundell and Bond (1998) argue that in the standard AR(1) model when the time series becomes highly persistent in the sense that "the value of the autoregressive parameter approaches unity or the variance of the individual effects increases relative to the variance of the disturbances", the lagged 
values of the series may be weak instruments for first differences. The firstdifferenced GMM estimator employing these weak instruments has been found to have poor finite sample properties in terms of bias and imprecision.

To tackle the weak instruments problem, Arellano and Bover (1995) and Blundell and Bond (1998) develop a "system GMM" estimator ${ }^{12}$ by considering a mean stationarity assumption on initial conditions in the sense that the mean of the distribution of the initial observations coincides with the mean of the steady-state distribution of the process. For the multivariate autoregressive model, Blundell and Bond (2000) show that a sufficient condition for the additional moment conditions to be valid is the joint mean stationarity of the series.

For this context the additional mean stationarity condition of $\left(y_{i t}, x_{i t}\right)$ enables the lagged first-differences of the series $\left(y_{i t}, x_{i t}\right)$ dated t-1 as instruments for the untransformed equations in levels. In addition to the moments for errors in differences described before, the system GMM estimator, denoted by SYS-GMM, is also based on the additional moments for errors in levels as follows,

$$
\begin{aligned}
E\left[\left(\begin{array}{c}
\Delta y_{i, t-1} \\
\Delta x_{i, t-1}
\end{array}\right)\left(y_{i t}-\alpha y_{i, t-1}-x_{i, t-1}^{\prime} \beta-\phi_{t}\right)\right] & =0 \\
t & =3, . ., 6
\end{aligned}
$$

As suggested by Blundell and Bond (1998), combining the first-differenced equations using suitably lagged levels as instruments, with levels equations using suitably lagged first-differences as instruments, the SYS-GMM estimator is expected to have much smaller finite sample bias and greater precision in the presence of persistent data.

Apart from the orthogonality conditions (6) and (7) stated above, the SYS-GMM estimator also makes use of the following moments for the periodspecific constants due to the existence of global shocks:

\footnotetext{
${ }^{12}$ Alonso-Borrego and Arellano (1999) propose the symmetrically-normalised GMM estimator and the Limited Information Maximum Likelihood estimator, and Hsiao et al. (2002) and Kruiniger (2002) develop the Maxmum Likelihood estimator.
} 


$$
\begin{aligned}
E\left(\Delta y_{i t}-\alpha \Delta y_{i, t-1}-\Delta x_{i, t-1}^{\prime} \beta-\Delta \phi_{t}\right) & =0 \\
t & =3, . ., 6
\end{aligned}
$$

To avoid the possible overfitting bias associated with using the full Arellano and Bond (1991) instrument set, this analysis uses restricted instrument sets suggested by Bowsher (2002), who proposes to selectively reduce the number of moment conditions for each first-differenced equation. More specifically, we only use lagged values of $y_{i t}$ and $x_{i t}$ from $t-2$ to $t-4$ as instruments. Accordingly, for SYS-GMM estimators the number of orthogonality conditions reduces to 31 in total, so that there are 24 overidentifying restrictions. Another way to avoid the possible overfitting bias is the introduction of two additional versions of SYS-GMM discussed below.

Three specification tests are conducted to address the consistency of SYS-GMM estimator, which mainly depends on the validity of the instruments. The first is a Serial Correlation test, which tests the null hypothesis of no first-order serial correlation and no second-order serial correlation in the residuals in the first-differenced equation. The second is a Sargan test of overidentifying restrictions, which is used to examine the overall validity of the instruments by comparing the moment conditions with their sample analogue. A finite sample correction is made to the two-step covariance matrix using the method due to Windmeijer (2005). The third is a difference Sargan test, denoted by Diff-Sargan, proposed by Blundell and Bond (1998), which examines the null hypothesis of mean stationarity for the SYS-GMM estimator. This statistic, called an incremental Sargan test statistic, is the difference between the Sargan statistics for first-differenced GMM and SYSGMM. It would be asymptotically distributed as a $\chi^{2}$ with $\mathrm{k}$ degrees of freedom, where $\mathrm{k}$ is the number of additional moment conditions.

\subsection{Empirical results}

This section presents the SYS-GMM estimates for equations (1) and (2). Two additional versions of SYS-GMM are also considered in order to circumvent overfitting and the possibility that the mean stationarity assumptions may be incorrect. While SYS-GMM-1 only uses $\Delta y_{i, t-1}$ as instruments 
in levels, SYS-GMM-2 only uses $\Delta x_{i, t-1}$ as instruments in levels. The OLS and within group estimates are also reported. Conventional wisdom has revealed that, although both of them are inconsistent for short panels, the OLS and WG estimates of the first order autoregressive parameter act as two extremes of the interval in which a consistent estimate of this parameter is expected to lie. ${ }^{13}$

Table 1. Does Private Investment Cause Financial Development? 1970-1998 (5-year-average Data)

\begin{tabular}{l|lllll}
\hline \hline Dependent Variable: $F D_{i t}$ & OLS & WG & SYS-GMM & SYS-GMM-1 & SYS-GMM-2 \\
\hline$F D_{i, t-1}$ & 0.880 & 0.597 & 0.806 & 0.741 & 0.578 \\
& {$[16.46]^{* * *}$} & {$[8.32]^{* * *}$} & {$[8.87]^{* * *}$} & {$[6.87]^{* * *}$} & {$[2.82]^{* * *}$} \\
& 2.785 & 5.091 & 5.286 & 6.745 & 3.779 \\
& {$[5.08]^{* * *}$} & {$[5.62]^{* * *}$} & {$[4.27]^{* * *}$} & {$[4.58]^{* * *}$} & {$[2.21]^{* *}$} \\
M1 (p-value) & & & & \\
M2 (p-value) & & & 0.00 & 0.00 & 0.05 \\
Sargan (p-value) & & & 0.89 & 0.92 & 0.69 \\
Diff-Sargan (p-value) & & & 0.36 & 0.24 & 0.44 \\
Granger Causality (p-value) & 0.00 & 0.00 & 0.87 & 0.76 & 1.00 \\
LR effect point estimate & 23.21 & 12.63 & 27.22 & 0.00 & 0.03 \\
(Standard error) & {$[9.70]^{* *}$} & {$[2.84]^{* * *}$} & {$[12.53]^{* *}$} & {$[9.04]^{* * *}$} & {$[7.61]$} \\
Observations & 212 & 212 & 212 & 212 & 212 \\
\hline \hline
\end{tabular}

Notes: 43 developing countries. Robust $t$ statistics in brackets below point estimates. *, **, *** significant at 10\%, 5\%, $1 \%$, respectively. The system GMM results are two-step estimates with heteroskedasticity-consistent standard errors and test statistics; the standard errors are based on finite sample adjustment of Windmeijer (2005). The M1 and M2 test the null of no first-order and no second-order serial correlation in first-differenced residuals. The Sargan tests the overidentifying restrictions for GMM estimators, asymptotically ? ${ }^{2}$. The Diff-Sargan tests the null of mean stationarity for system GMM estimators in which SYS-GMM uses standard moment conditions, while SYS-GMM-1 only uses lagged first-differences of FD dated $\mathrm{t}-1$ as instruments in levels and SYS-GMM-2 only uses lagged firstdifferences of PI dated $\mathrm{t}-1$ as instruments in levels. The Granger causality test is used to examine the null hypothesis that private investment doesn't Granger-cause financial development. LR measures the long-run effect of private investment on financial development. Its standard error is approximated using the delta method.

Table 1 presents the results for causality going from private investment to financial development. The OLS level and Within Group estimates for the lagged dependent variable form an interval in which the system GMM estimates fall. The specification tests for three versions of SYS-GMM indicate that we can reject the null that the error term in first differences exhibits

\footnotetext{
${ }^{13}$ Bond et al. (2001) and Bond (2002) illustrate that in principle the first-differenced GMM estimates for the $\operatorname{AR}(1)$ coefficient should lie between the Within Group estimates (being downwards biased) and the OLS estimates (being upwards biased) from a straightforward pooled regression.
} 
no first-order serial correlation and cannot reject the hypothesis that there is no second-order serial correlation. The Sargan tests in three models do not signal the instruments are invalid. The difference Sargan for SYS-GMM cannot reject the null of the additional moment conditions being valid. The Granger-noncausality test for the SYS-GMM estimates clearly rejects the null hypothesis, suggesting that there is a causal effect going from private investment to financial development. The Long Run (LR) effect estimate of SYS-GMM indicates that this effect tends to persist into the long run. The SYS-GMM-1 estimates further confirm the findings.

Table 2. Does Financial Development Cause Private Investment? 1970-1998 (5-year-average Data)

\begin{tabular}{l|lllll}
\hline \hline Dependent Variable: $P I_{i t}$ & OLS & WG & SYS-GMM & SYS-GMM-1 & SYS-GMM-2 \\
\hline$P I_{i, t-1}$ & 0.744 & 0.232 & 0.521 & 0.490 & 0.424 \\
& {$[14.04]^{* * *}$} & {$[3.12]^{* * *}$} & {$[4.27]^{* * *}$} & {$[3.75]^{* * *}$} & {$[3.00]^{* * *}$} \\
$F D_{i, t-1}$ & 0.008 & 0.010 & 0.015 & -0.008 & 0.022 \\
& {$[2.09]^{* *}$} & {$[1.67]^{*}$} & {$[2.32]^{* *}$} & {$[0.85]$} & {$[2.11]^{* *}$} \\
& & & & & \\
M1 (p-value) & & & 0.00 & 0.01 & 0.01 \\
M2 (p-value) & & & 0.34 & 0.51 & 0.26 \\
Sargan (p-value) & & & 0.50 & 0.40 & 0.31 \\
Diff-Sargan (p-value) & & & 0.83 & 0.75 & 0.48 \\
Granger Causality (p-value) & 0.04 & 0.10 & 0.03 & 0.40 & 0.04 \\
LR effect point estimate & 0.03 & 0.01 & 0.03 & -0.02 & 0.04 \\
(Standard error) & {$[0.01]^{* *}$} & {$[0.01]^{*}$} & {$[0.01]^{* *}$} & {$[0.02]$} & {$[0.01]^{* *}$} \\
Observations & 198 & 198 & 198 & 198 & 198 \\
\hline \hline
\end{tabular}

Notes: 43 developing countries. The Granger causality test is used to examine the null hypothesis that financial development doesn't Granger-cause private investment. See Table 1 for more notes.

In Table 2 we turn to whether financial development Granger causes private investment. The specification tests indicate that the models associated with three types of SYS-GMM are well specified. More specifically, we can reject no first-order serial correlation but cannot reject the hypothesis that there is no second-order serial correlation. Sargan tests and difference Sargan tests suggest that neither the instruments and mean stationarity conditions are invalid. Both SYS-GMM and SYS-GMM-2 ${ }^{14}$ show a positive

\footnotetext{
${ }^{14}$ The SYS-GMM-1 and SYS-GMM-2 in general serve as robustness tests to the SYS-
} 
causal effect going from financial development to private investment, not only in the short-run but also in the long-run.

In the following a set of experiments are conducted to test whether the above findings are robust to various model specifications. We firstly consider including GDP per capita in logs and trade openness separately as additional regressors. Appendix Table 4 considers the inclusion of GDP in logs. SYSGMM estimates in the upper panel suggest that the finding on a causal effect of private investment on financial development is robust to this inclusion, while the SYS-GMM estimates in the lower panel show that GDP in logs picks up the effects of financial development on private investment, that is to say, the causal effect of financial development on private investment is found to work partly through real GDP. Appendix Table 5 clearly indicates that the inclusion of trade openness does not alter the pattern of the findings. Finally we investigate the causality with $\operatorname{AR}(2)$ models. The second lags of the dependent variables are insignificant in the two panels of Appendix Table 6, as suggested by the SYS-GMM estimates. In addition to the first lags of PI and FD being significant in two panels respectively, the second lag of private investment is observed to be significantly associated with financial development.

In sum, by using the system-GMM estimation method on averaged data controlling for the possibility of endogeneity bias and omitted variable bias, this analysis finds positively significant causation in both directions between private investment and financial development for 43 developing countries, and indicates that a high degree of persistence exists in the averaged data of FD and PI. The findings are robust to various specifications. However, it is worth noting that the asymptotic properties of the system-GMM estimator depend on having a large number of cross-section units. Concerns remain regarding the finite sample bias for this context. The findings still wait for further confirmation from the analysis on pooled annual data that will be

GMM in two tables. Both SYS-GMM-1 in Table 1 and SYS-GMM-2 in Table 2 produce consistent findings with their counterparts, respectively. However, using the lagged firstdifferences of PI dated t-1 as instruments in levels, SYS-GMM-2 in Table 1 and SYSGMM-1 in Table 2 do not confirm the findings by their respective SYS-GMMs, especially the latter, perhaps suggesting that the moment conditions using lagged first-differences of PI dated t-1 may not contain much information. 
undertaken in the next section.

\section{Analysis on annual data}

Using averaged data has a number of advantages, as well documented in the literature, but its limitations are also notable. Averaging data over fixed intervals (typically over 5 or 10 years) arbitrarily modifies the time series dimension so that information loss is inevitable. Although averaging data has the potential for removing business cycle fluctuations, it is not guaranteed that such fluctuations are eliminated effectively given the varied length of business cycles across countries and over time. Moreover, methods like GMM imposing homogeneity over all slope coefficients fail to capture potential cross sectional heterogeneity in the parameters.

This section moves on to explore the link between private investment and financial development by using pooled annual data. In principle, annual data can be more informative than averaged data in examining the relevant effect. By explicitly looking at the yearly time series variation, one can explore the existence of heterogeneity across countries adequately and estimate the parameters of interest more precisely.

As widely pointed out, assuming cross section error independence fails to reflect a reality in which financial market integration and business cycle synchronization are key features of a global economy. The analysis in this section attempts to study causality between private investment and financial development in a world where the existence of global shocks causes cross section dependence across countries.

The remainder of this section proceeds as follows. Subsection 4.1 sets out the common factor approach due to Bai and Ng (2004). Subsection 4.2 contrasts the panel unit root test of Bai and Ng (2004) with Maddala and $\mathrm{Wu}$ (1999) Fisher test, which is associated with the assumption of cross section independence. Subsection 4.3 conducts the panel cointegration test of Pedroni $(1999,2004)$ on observed data and defactored data. Subsection 4.4 adopts the Pesaran (2006a) Common Correlated Effect approach to estimate the models. 


\subsection{Methodology: Common factor approach}

Assume the interactions between financial development (FD) and private investment over GDP (PI) are represented by the unrestricted autoregressive distributed lag $\operatorname{ARDL}(\mathrm{p}, \mathrm{p})$ systems:

$$
\begin{aligned}
\mathbf{F D}_{i t} & =\sum_{j=1}^{p} \alpha_{1 i j} \mathbf{F D}_{i, t-j}+\sum_{j=1}^{p} \beta_{1 i j} \mathbf{P I}_{i, t-j}+\lambda_{1 i}^{\prime} f_{1 t}+v_{1 i t} \\
\mathbf{P I}_{i t} & =\sum_{j=1}^{p} \alpha_{2 i j} \mathbf{P I}_{i, t-j}+\sum_{j=1}^{p} \beta_{2 i j} \mathbf{F D}_{i, t-j}+\lambda_{2 i}^{\prime} f_{2 t}+v_{2 i t} \\
i & =1,2, \ldots, 43 \text { and } t=2, \ldots, 29
\end{aligned}
$$

For the sake of simplicity, denoting by $y$ the dependent variable (either FD or PI) and by $x$ s the explanatory variables other than the lagged dependent variable, we have

$$
\begin{aligned}
\mathbf{y}_{i t} & =\sum_{j=1}^{p} \alpha_{i j} \mathbf{y}_{i, t-j}+\sum_{j=1}^{p} \beta_{i j} \mathbf{x}_{i, t-j}+\lambda_{i}^{\prime} f_{t}+v_{i t} \\
i & =1,2, \ldots, 43 \text { and } t=2, \ldots, 29
\end{aligned}
$$

where $f_{t}$ is a $(r \times 1)$ vector of unobserved common factors, and $\lambda_{i}$ is a factor loading vector, such that $\lambda_{i}^{\prime} f_{t}=\lambda_{i 1}^{\prime} f_{t 1}+\lambda_{i 2}^{\prime} f_{t 2} \ldots .+\lambda_{i r}^{\prime} f_{t r}$ (here $r$ is the number of common factors). The common factors could be a global trend component, a global cyclical component, common technological shocks or macroeconomic shocks that cause cross section dependence. $v_{i t}$ are errors assumed to be serially uncorrelated and independently distributed across countries. We allow for richer dynamics in the representations to control for business cycle influences, while the current value of $\mathbf{x}, \mathbf{x}_{i t}$, is excluded to avoid a potential endogeneity problem.

The above representations with a factor structure are believed to be very general. Bai (2005) points out that the interactive effects model including the interaction between factors, $f_{t}$, and factor loadings, $\lambda_{i}$, is more general than an additive effects model, the traditional one-way or two-way fixed 
effects model ${ }^{15}$.

Since the common factors are unobservable, standard regression methods are not applicable for an equation like (11). Estimation of models with a common factor structure is still at its early stage of development. Pesaran (2006a) estimates this type of model directly by proxying the common factors with weighted cross section averages (subsection 4.4 discusses this in detail). In spite of its convenience of not involving estimation of common factors, the Pesaran (2006a) approach is confined to the single factor case. Among others, Bai and Ng (2004) and Moon and Perron (2004) seek to estimate the common factors. Their approaches have advantages in accommodating multiple common factors that may coexist in the economy, effectively contributing to panel unit root testing, panel cointegration testing and estimation of models in a more general setting. Below is a brief description of common factor analysis due to Bai and Ng (2004).

To overcome possible cross section dependence in panel unit root testing, Bai and Ng (2004) propose a PANIC approach - Panel Analysis of Nonstationarity in Idiosyncratic and Common Components. Essentially they assume the DGP of a series $z_{i t}$ (which could be $\mathbf{y}_{i t}$ or $\mathbf{x}_{i t}$ for this case) has a common factor structure in the sense that the series is the sum of an unobserved deterministic component $\left(d_{i t}\right)$, an unobserved common component $\left(\lambda_{i}^{\prime} f_{t}\right)$ and an idiosyncratic component $\left(e_{i t}\right)$ as follows:

$$
z_{i t}=d_{i t}+\lambda_{i}^{\prime} f_{t}+e_{i t}
$$

where $f_{t}$ is a vector of unobserved common factors and $\lambda_{i}$ is the factor loading vector as defined before. The common component and idiosyncratic component could be stationary or nonstationary and are allowed to be integrated of different orders. The common factor $\left(f_{t}\right)$ and the idiosyncratic component $\left(e_{i t}\right)$ can be expressed as:

$$
\begin{aligned}
f_{k t} & =\alpha_{k} f_{k, t-1}+v_{i t} \\
e_{i t} & =\rho_{i} e_{i, t-1}+\varepsilon_{i t}
\end{aligned}
$$

\footnotetext{
${ }^{15}$ For the case of $\mathrm{r}=2$, when $f_{t}=\left(1 \eta_{t}\right)^{\prime}$ and $\lambda_{i}^{\prime}=\left(\alpha_{i} 1\right)$, we have $\lambda_{i}^{\prime} f_{t}=\alpha_{i}+\eta_{t}$, where $\alpha_{i}$ and $\eta_{t}$ are the individual effect and time effect, respectively.
} 
The factor $k$ is stationary if $\alpha_{k}<1$ while the idiosyncratic component $\left(e_{i t}\right)$ is stationary if $\rho_{i}<1$. When the idiosyncratic component $\left(e_{i t}\right)$ is stationary, conventional wisdom suggests that the factors can be estimated by using principal component analysis. As a crucial step Bai and Ng (2004) propose to apply a principal components analysis on the differenced data (when a linear trend is not allowed) or differenced and demeaned data (when a linear trend is allowed) to estimate the factors for the case where $e_{i t}$ is integrated of order one.

To estimate the factors, the following two steps should be taken:

The first step is to estimate the number of common factors, which is discussed by Bai and Ng (2002) and Moon and Perron (2004). Bai and Ng (2002) suggest using a principal component analysis on the observed data to calculate the number of factors ${ }^{16}$. For any arbitrary $k(k<\min \{N, T\})$, the estimates of $\lambda^{k}$ and $f^{k}$ are derived by solved the following minimization problem $\left(d_{i t}=0\right.$ is assumed for simplicity):

$$
\begin{aligned}
V(k) & =\min _{\Lambda^{k}, f^{k}}(N T)^{-1} \sum_{i=1}^{N} \sum_{j=1}^{T}\left(z_{i t}-\lambda_{i}^{k^{\prime}} f_{t}^{k}\right)^{2} \\
\text { s.t. } \frac{\Lambda^{k^{\prime}} \Lambda^{k}}{N} & =I_{k} \text { or } \frac{f^{k^{\prime}} f^{k}}{T}=I_{k}
\end{aligned}
$$

where $f_{t}=\left(f_{t 1}, f_{t 2}, f_{t 3}, \ldots f_{t r}\right)^{\prime}, \lambda_{i}=\left(\lambda_{i 1}, \lambda_{i 2}, \lambda_{i 3} \ldots \lambda_{i r}\right)^{\prime}, \Lambda_{i}=\left(\lambda_{1}, \lambda_{2}\right.$, $\left.\lambda_{3} \ldots \lambda_{N}\right)^{\prime}$ and $f$ is the $(T \times r)$ matrix of common components. Typically when $T<N$, the normalization that $\frac{f^{k^{\prime}} f^{k}}{T}=I_{k}$ is used ${ }^{17}$. The estimated factor matrix, denoted by $\widetilde{f^{k}}$, can be expressed as $\sqrt{T}$ times the eigenvectors corresponding to the $k$ largest eigenvalues of the $T \times T$ matrix $z z^{\prime}$. Given $\widetilde{f^{k}}$, the estimated factor loading matrix, denoted by $\widetilde{\Lambda^{k}}$, can be computed by $\frac{z^{\prime} \widetilde{f^{k}}}{T}$.

Given $\widetilde{f^{k}}$ and $\widetilde{\Lambda^{k}}$, Bai and $\mathrm{Ng}$ (2002) propose to determine the number of factors by minimizing one of the following criterion functions:

\footnotetext{
${ }^{16}$ Bai (2004) suggests that differenced data can also be used to calculate the number of factors.

${ }^{17}$ The normalization that $\frac{\Lambda^{k^{\prime}} \Lambda^{k}}{N}=I_{k}$ is used when $T>N$.
} 


$$
\begin{aligned}
P C(k) & =V\left(k, \widetilde{f^{k}}\right)+k g(N, T) \\
I C(k) & =\ln \left[V\left(k, \widetilde{f^{k}}\right)\right]+k g(N, T)
\end{aligned}
$$

where $V\left(k, \widetilde{f^{k}}\right)=(N T)^{-1} \sum_{i=1}^{N} \sum_{j=1}^{T}\left(\varepsilon_{i}^{\prime} \varepsilon_{i}\right)$ is a measure of fit, and $g(N, T)$ is a penalty function that depends on the size of panel. The criterion functions capture a trade off between measures of fit and a penalty function. When the number of factors increases, the fit must improve, but the penalty goes up. Bai and $\mathrm{Ng}$ (2002) provide three criterion functions for $P C(k)$ and $I C(k)$, respectively. In general, $I C(k)$ is easier to use since it does not involve the estimation of a penalty function which requires the choice of a bounded integer (kmax).

The integer minimizing a criterion function is the estimated number of factors.

The second step is to estimate the common component and idiosyncratic component once the true number of factors, denoted by $r$, has been worked out. Let $Z_{i t}$ be the differenced data (without a linear trend) or differenced and demeaned data (with a linear trend) of observed data $z_{i t}{ }^{18}$. The principal component estimator of the factor matrix $f$, denoted by $\widehat{f}$, is $\sqrt{T-1}$ times the eigenvectors corresponding to the $r$ largest eigenvalues of the $(T-1) \times$ $(T-1)$ matrix $Z Z^{\prime}$. Given $\widehat{f}$, the estimated factor loading matrix, denoted by $\widehat{\Lambda}$, can be computed by $\frac{Z^{\prime} \widehat{f}}{T-1}$.

The approach above yields $r$ estimated common factors $\widehat{f}_{t}$ and associated factor loadings $\widehat{\lambda}_{i}$. The estimated idiosyncratic component takes the form of

$$
\widehat{e}_{i t}=Z_{i t}-\widehat{\lambda}_{i}^{\prime} \widehat{f}_{t}
$$

To remove the effect of possible overdifferencing, Bai and Ng (2004) suggest to recumulate the estimated common factors, $\widehat{f}_{t}$, and estimated idiosyncratic component, $\widehat{e}_{i t}$, yielding

\footnotetext{
${ }^{18}$ Bai and $\mathrm{Ng}(2004)$ recommend to firstly standardise the data, although the PANIC approach does not require it.
} 


$$
\begin{aligned}
\widehat{F}_{t} & =\sum_{s=2}^{t} \widehat{f}_{s} \\
\widehat{E}_{i t} & =\sum_{s=2}^{t} \widehat{e}_{i s} \\
t & =2, \ldots T
\end{aligned}
$$

The resulting idiosyncratic component, $\widehat{E}_{i t}$, is in fact the defactored data corresponding to the observed data $z_{i t}$.

\subsection{Panel unit root tests}

Over recent decades a number of panel unit root testing procedures have been proposed in the literature to increase the power of univariate unit root tests, such as Im et al. (2003), Levin et al. (2002) and Maddala and Wu (1999). Associated with the unrealistic assumption of cross section independence, these testing procedures are often classified as the first generation of panel unit root tests. Since the influential work by Banerjee et al. (2004), testing for unit roots in heterogeneous panels under the assumption of cross section dependence has attracted a great deal of attention. The testing procedures proposed by Pesaran (2006b), Moon and Perron (2004) and Bai and $\mathrm{Ng}$ (2004) are among the second generation of panel unit root tests.

With a common factor structure presented earlier, Bai and Ng (2004) note that the nonstationarity of series with a factor structure originates from the nonstationarity of either the common component or idiosyncratic component or both. Bai and $\mathrm{Ng}$ (2004) test for unit roots for the common component and idiosyncratic component, $\widehat{E}_{i t}$, separately. For the idiosyncratic component, Bai and $\mathrm{Ng}$ (2004) propose to test the following ADF equation by using the (defactored) estimated idiosyncratic component, $\widehat{E}_{i t}$, with no deterministic term:

$$
\Delta \widehat{E}_{i t}=d_{i 0} \widehat{E}_{i t}+d_{i 1} \Delta \widehat{E}_{i t-1} \ldots+d_{i p} \Delta \widehat{E}_{i t-p}+\mu_{i t}
$$

They propose to use the Fisher P-test as suggested by Maddala and Wu (1999) on the above ADF equation. 
For the nonstationarity of the common factors, Bai and Ng (2004) distinguish two cases. When there is only one common factor, a standard ADF test with an intercept is suggested:

$$
\Delta \widehat{F}_{t}=D_{t}+\theta_{0} \Delta \widehat{F}_{t-1}+\sum_{j=1}^{p} \theta_{j} \Delta \widehat{F}_{t-j}+v_{i t}
$$

When there is more than one common factor, Bai and Ng (2004) propose an interactive procedure, analogous to the Johansen trace test for cointegration.

Appendix Table 7 reports the values of information citerion $\mathrm{IC}_{p 1}(k)$ ( Bai and $\mathrm{Ng}, 2002)$ for the series of $\mathrm{FD}$ and $\mathrm{PI}^{19}$. When $r=1$, the $\mathrm{IC}_{p 1}(k)$ values for both FD and PI are minimized, clearly suggesting that there is only one common factor for FD and PI, respectively. The time series of the common factors for FD and PI are presented in Appendix Figure 1.

Table 3 contrasts the panel unit root test proposed by Maddala and $\mathrm{Wu}$ (1999) and Bai and $\mathrm{Ng}$ (2004). The former is related to the assumption of cross section independence while the latter is defined under the assumption of cross section dependence. The Maddala and Wu (1999) Fisher test, which does not require a balanced panel, indicates the series of FD and PI may be $\mathrm{I}(1)$ processes no matter whether a trend is allowed. Controlling for the common factor, the Bai and $\mathrm{Ng}$ (2004) approach suggests that the series for FD and PI are I(1) variables when we allow for a trend.

\footnotetext{
${ }^{19}$ The data for FD and PI are standardised at the outset. The PANIC approach essentially requires a balanced panel. To overcome the problem of missing data, imputation within each region is conducted since countries in a region tend to have similar income levels, closer economic relations and be more dependent on each other. There are 49 observations imputed for FD and 64 observations for PI, corresponding to $4 \%$ and $5 \%$ of full values in the resulting balanced panels, respectively. Appendix Table 3 presents the list of countries in each region.
} 
Table 3. Unit Root Tests in Heterogeneous Panels

\begin{tabular}{|c|c|c|c|c|}
\hline & \multicolumn{4}{|c|}{ Maddala and Wu (1999) Fisher Test } \\
\hline & \multicolumn{2}{|c|}{ Without Trend } & \multicolumn{2}{|l|}{ With Trend } \\
\hline \multirow[t]{2}{*}{ FD } & \multicolumn{2}{|l|}{65.143} & \multicolumn{2}{|l|}{71.679} \\
\hline & \multicolumn{2}{|l|}{ [0.95] } & \multicolumn{2}{|l|}{$[0.87]$} \\
\hline \multirow[t]{2}{*}{ PI } & \multicolumn{2}{|l|}{97.754} & \multicolumn{2}{|l|}{94.101} \\
\hline & {$[0.18]$} & & \multicolumn{2}{|l|}{$[0.26]$} \\
\hline & \multicolumn{4}{|c|}{ Bai and Ng (2004) Test } \\
\hline & \multicolumn{2}{|c|}{ FD } & \multicolumn{2}{|l|}{ PI } \\
\hline & Without Trend & With Trend & Without Trend & With Trend \\
\hline \multirow[t]{2}{*}{ Common Components (ADF) } & -2.713 & -3.099 & -1.981 & -2.202 \\
\hline & {$[0.07]^{*}$} & {$[0.11]$} & {$[0.29]$} & {$[0.49]$} \\
\hline \multirow[t]{2}{*}{ Idiosyncratic Components (P test) } & 214.555 & 199.876 & 79.206 & 55.067 \\
\hline & {$[0.00]^{* * *}$} & {$[0.00]^{* * *}$} & {$[0.68]$} & {$[1.00]$} \\
\hline Unit Root & no & yes & yes & yes \\
\hline
\end{tabular}

Note: The upper panel presents the results of Maddala and Wu (1999) Fisher Test on the observed data under the null hypothesis of a unit root. The lower panel reports the Bai and $\mathrm{Ng}(2004)$ test, which decomposes the errors and conducts the unit root tests for the common components (ADF test) and idiosyncratic components (Maddala and Wu (1999) Fisher test) separately. P-values are in brackets.

\subsection{Panel cointegration tests}

When both FD and PI are integrated, cointegration between the two variables is possible. This section uses panel cointegration techniques to investigate the existence of a long run relationship between them. Banerjee et al. (2004) point out that "cointegration across units and within each unit may not be easily differentiatied due to the presence of cross section cointegration". The analysis of panel cointegration allowing for cross section dependence is still in its infancy of development. Motivated by Gengenbach et al. (2005) who suggest the use of defactored data, $\widehat{E}_{i t}$, in panel cointegration testing to control for cross section dependence, this section contrasts the Pedroni $(1999,2004)$ residual-based panel cointegration tests using observed data and defactored data.

The Pedroni (2004) test, widely used in empirical research in recent years, assumes cross section independence of panel units but allows for some heterogeneity in the cointegrating relationships. He proposes two classes of statistics based on individual OLS residuals of the single cointegration regression below to test the null hypothesis of no cointegration: 


$$
\mathbf{y}_{i t}=\alpha_{i}+\mathbf{x}_{i, t}^{\prime} \delta_{i t}+u_{i t}
$$

One class is the "panel" statistics ${ }^{20}$, which are constructed by taking the ratio of the sum of the numerators and the sum of denominators of individual unit root statistics across the within dimension of the panel with a homogeneity restriction, and the other is the "group mean" statistics ${ }^{21}$, which are based on the averages of individual unit root statistics along the between dimension of the panel allowing for heterogeneity.

Table 4. Panel Cointegration Tests between FD and PI

\begin{tabular}{l|llll}
\hline \hline & \multicolumn{2}{|c}{ Observed Data } & \multicolumn{2}{c}{ Defactored Data } \\
\cline { 2 - 5 } & Without trend & With trend & Without trend & With trend \\
\hline Panel ADF & 1.749 & 1.039 & -3.956 & -6.311 \\
Group ADF & 2.661 & 1.360 & -3.822 & -5.855 \\
& & & & \\
\hline \hline
\end{tabular}

Note: This table reports the Pedroni $(1999,2004)$ cointegration test. The number of lag truncations used in the calculation of the Pedroni statistics is 4 . These are one-sided tests with an critical value of -1.64 . Under the null hypothesis of no cointegration, the test statistic is asymptotically distributed as a standard normal.

Pedroni (2004) shows that the ADF-based tests perform better when the sample size is small. Table 4 reports the group and panel ADF statistics of Pedroni $(1999,2004)$ using observed data and defactored data, both with and without a deterministic trend. The result associated with using observed data shows, when common factors are allowed, the presence of cross section dependence might render the Pedroni test unable to detect the cointegration relationship in question. However, when common factors are extracted, the null of no cointegration can always be rejected clearly, no matter whether we allow for a trend ${ }^{22}$. This table indicates a stationary long-run relationship exists between financial development and private investment, and highlights

\footnotetext{
${ }^{20}$ Four "panel" statistics are a "variance ratio" statistic $\left(Z_{\widehat{v} N T}\right)$, a "panel-t" statistic $\left(Z_{\widehat{t} N T}\right)$, a "panel-rho" statistic $\left(Z_{\widehat{\rho} N T-1}\right)$ and a "panel-ADF" statistic $\left(Z_{\widehat{a d f} N T}\right)$.

${ }^{21}$ Three "group mean" statistics are a "group-t" statistic $\left(\widetilde{Z}_{\hat{t} N T}\right)$, a "group-rho" statistic $\left(\widetilde{Z}_{\widehat{\rho} N T-1}\right)$ and a "group-ADF" statistic $\left(\widetilde{Z}_{\widehat{a d f} N T}\right)$.

${ }^{22}$ The Pedroni test based on defactored data should be interpreted with caution, since the defactored data are estimated data and may be subject to particular forms of measurement errors.
} 
allowing for cross section dependence as an important source of information for this analysis.

\subsection{Estimation on annual data}

Study of the estimation of large cross section and time series panel datasets with a common factor structure has been fairly scarce. This section undertakes the Pesaran (2006a) common correlated effects approach for the estimation of heterogeneous panels with common factors. Section 4.4.1 sets out the estimation methods associated with both cross section error independence and cross section error dependence. Section 4.4 .2 presents the empirical evidence.

\subsubsection{Estimation methods}

Given the series of financial development and private investment appear to be cointegated, there must be a vector error correction representation, as shown by Engle and Granger (1987), governing the comovements of the series of financial development and private investment over time. The corresponding error correction equation to Equation (11) is as follows:

$$
\begin{aligned}
\Delta \mathbf{y}_{i t}= & \pi_{p}\left(\mathbf{y}_{i, t-p}-\frac{\phi_{p}}{-\pi_{p}} \mathbf{x}_{i, t-p}\right)+\sum_{j=1}^{p-1} \pi_{j} \Delta \mathbf{y}_{i, t-j}+\sum_{j=1}^{p-1} \phi_{j} \Delta \mathbf{x}_{i, t-j} \\
& +\lambda_{i}^{\prime} f_{t}+v_{i t} \\
i= & 1,2, \ldots, 43 \text { and } t=2, \ldots, 29
\end{aligned}
$$

where

$$
\begin{aligned}
\phi_{r} & =\sum_{r=1}^{p} \beta_{i r} \\
\pi_{r} & =\sum_{r=1}^{p} \alpha_{i r}-1
\end{aligned}
$$

In the absence of common factors, the within groups (WG) approach, mean group (MG) approach of Pesaran and Smith (1995) and pooled mean 
group (PMG) approach of Pesaran et al. (1999) are especially suited to the analysis of panels with large time and large cross-section dimensions. The consistency of the WG estimator for the dynamic homogeneous model is

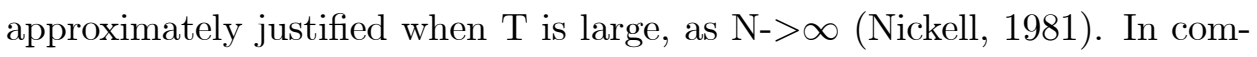
parison to the WG method, which only allows the intercept to vary across countries but imposes homogeneity on all slope coefficients, the MG and PMG approaches allow for considerable heterogeneity across countries. The MG approach applies an OLS regression for each country to obtain individual slope coefficients, and then averages the country-specific coefficients to derive a long-run parameter for the panel. More specifically, the MG estimator and its standard errors are calculated as follows:

$$
\begin{aligned}
\widehat{\theta}_{M G} & =\bar{\theta}=\frac{\sum_{i=1}^{N} \widehat{\theta}_{i}}{N} \\
\operatorname{se}\left(\widehat{\theta}_{M G}\right) & =\frac{\sigma\left(\widehat{\theta}_{i}\right)}{\sqrt{N}}=\frac{\sqrt{\sum_{i-1}^{N} \frac{\left(\widehat{\theta}_{i}-\bar{\theta}\right)^{2}}{N-1}}}{\sqrt{N}}
\end{aligned}
$$

For small samples, the MG estimator is likely to be inefficient although it is still consistent.

Unlike the MG approach, which imposes no restriction on slope coefficients, the PMG approach imposes cross-section homogeneity restrictions only on the long-run coefficient, but allows short-run coefficients, the speeds of adjustment and the error variances to vary across countries. The restriction of long-run homogeneity can be tested via a Hausman test. Under the null hypothesis of long-run homogeneity, the PMG estimators are consistent and more efficient than the MG estimators. Moreover, Pesaran et al. (1999) show that the PMG estimators are consistent and asymptotically normal irrespective of whether the underlying regressors are $\mathrm{I}(1)$ or $\mathrm{I}(0)$.

The PMG approach requires that the coefficients for $\mathbf{x}_{i, t-p}$ are common across countries, that is, 


$$
\begin{aligned}
\phi_{r} & =\sum_{r=1}^{p} \beta_{r} \\
\pi_{r} & =\sum_{r=1}^{p} \alpha_{r}-1
\end{aligned}
$$

When common factors are allowed, Pesaran (2006a, 2006b) suggests the use of the (weighted) cross sectional averages of the dependent variable and individual specific regressors to proxy the common factors. More specifically, he proposes to augment the observed regressors with the (weighted) cross sectional averages of the dependent variable and the individual specific regressors such that as the number of cross section units goes to infinity, the effects of unobserved common factors can be eliminated.

Pesaran (2006a) proposes two common correlated effect (CCE) approaches for large heterogeneous panels whose errors contain unobserved common factors. One is the common correlated effect pooled (CCEP) estimator, a generalization of the within groups estimator that allows for the possibility of cross section correlation, and the other is the common correlated effects mean group (CCEMG) estimator, a generalization of the mean group estimator of Pesaran and Smith (1995) that is adapted for the possibility of cross section correlation. The CCEP estimator is the within groups estimator with interactions between country dummies and means of the dependent variable and individual specific regressors as well as time dummies included in the model. The CCEMG approach uses OLS to estimate an auxiliary regression for each country in which the time dummies and the (weighted) cross sectional averages of the dependent variable and the individual specific regressors are added, the coefficients and standard errors are then computed according to Equation (25) and (26).

The Pesaran (2006a, 2006b) approach exhibits considerable advantages. It does not involve estimation of unobserved common factors and factor loadings. It allows unobserved common factors to be possibly correlated with exogenous regressors and exert differential impacts on individual units. It permits unit root processes amongst the observed and unobserved common effects. The proposed estimator is still consistent, although it is no longer 
efficient, when the idiosyncratic components are not serially uncorrelated.

In this context, the cross section means of $\Delta F D_{i t}, F D_{i, t-1}, \Delta P I_{i t}$, $P I_{i, t-1}$, and time dummies are included. The CCEP and CCEMG estimators have been shown to be asymptotically unbiased and consistent as $\mathrm{N}->$ $\infty$ and $\mathrm{T}->\infty$, and to have generally satisfactory finite sample properties. The asymptotic distribution of the CCEMG estimator is free of nuisance parameters as $N$ and $T$ go to infinity, without any restriction on the convergence rate of $N$ and $T$. More importantly, the CCEMG estimator holds for any number of unobserved common factors as long as the number is fixed, which is especially attractive.

A common correlated effects pooled mean group (CCEPMG) estimator is introduced in this study, which is a generalization of the pooled mean group estimator of Pesaran et al. (1999) that also allows for the possibility of cross section correlation. The restriction of long-run homogeneity can also be tested via a Hausman test. Under the null hypothesis of long-run homogeneity, the CCEPMG estimators are expected to be consistent and more efficient than the CCEMG estimators.

\subsubsection{Estimation results}

Table 5 examines whether private investment causes financial development for 43 developing countries over 1970-98, while Table 6 studies causality in the reverse direction. Tables 5 and 6 contrast the CCEP, CCEMG and CCEPMG estimates with their counterparts, the WG, MG and PMG estimates. The first group of estimates is associated with the assumption of errors being cross sectionally dependent, while the latter group assumes cross section error independence. An autoregressive distributed lag $\operatorname{ARDL}(3,3)$ system has been adopted for this analysis ${ }^{23}$.

We look first at the case of cross section error dependence. The coefficients corresponding to the speeds of adjustment in the two tables are significantly different from zero, suggesting that two-way Granger causalities exist in the cointegrated system.

\footnotetext{
${ }^{23}$ The number of lags is constrained by the number of observations. As shown by Pesaran et al. (1999), the PMG estimator seems quite robust to outliers and the choice of ARDL order.
} 
Imposing homogeneity on all slope coefficients except for the intercept, the CCEP estimates in two tables suggest that there are positive long-run effects going in two directions. When heterogeneity is sought, the CCEMG and CCEPMG are called for. The CCEMG estimates find that the longrun effects are less precisely estimated for both directions. This is of no surprise - the long-run effects become much harder to capture when full heterogeneity is allowed. Nevertheless, it does imply that heterogeneity is especially prominent in this context. Moving from the CCEMG (no restriction, but potentially inefficient) to CCEPMG (a common long-run effect required) changes the results significantly, in particular, imposing long-run homogeneity reduces the standard errors and the speeds of adjustment. The restriction cannot be rejected at a conventional level by a Hausman test. The CCEPMG estimates provide evidence in support of significant long-run effects in both directions.

After controlling for error dependence and heterogeneity across countries, the CCEPMG estimates clearly suggest positive long-run effects going in both directions between private investment and financial development, which is consistent with the findings shown by the system GMM estimates on the averaged data. However the system GMM approach in principle assumes error independence and homogeneity across countries. Does this mean that controlling for error dependence and heterogeneity across countries is potentially redundant?

Comparing the above case with the case of cross section error independence is worthwhile. As its counterpart associated with cross section error dependence, the WG estimates (restrictions on all slope coefficients except for the intercept) show positive long-run effects in both directions, in accordance with the findings shown by the system GMM estimates on the averaged data. Allowing for heterogeneity across countries but no error dependence across countries, the MG approach finds no evidence in support of significant long-run effects in both directions. Supported by the Hausman tests in Table 5 and Table 6, the PMG estimates indicate a significant longrun effect going from private investment to financial development, but not vice versa. This tends to underscore the importance of allowing for heterogeneity across countries in the sense that, compared to the PMG approach, 
Table 5. Does Private Investment Cause Financial Development? 1970-1998

(Annual Data)

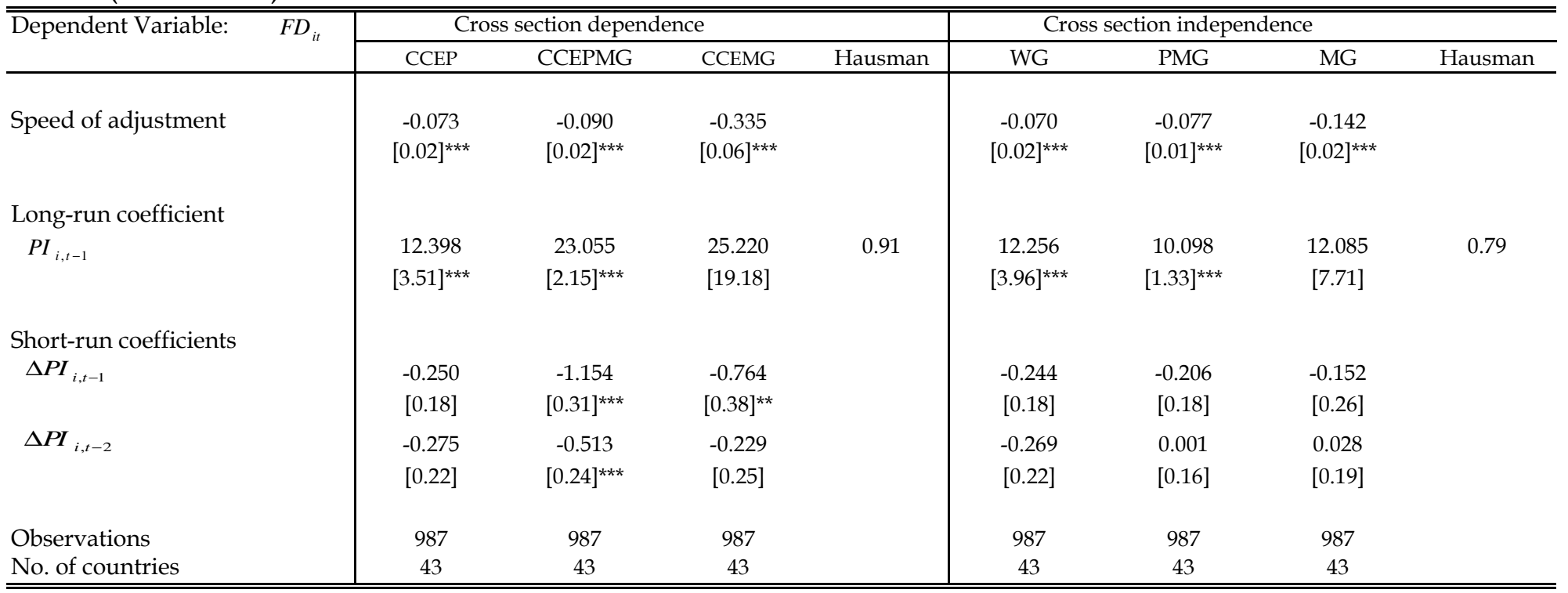

Note: This table presents the Pesaran (2006a) CCEP and CCEMG estimates, and CCEPMG estimates defined in the text under the assumption of cross section error

dependence, and their counterparts associated with the assumption of cross section error independence including the Within Group estimates (WG), Pesaran and Smith (1995)

Mean Group (MG) and Pesaran et al. (1999) Pooled Mean Group (PMG) estimates. The PMG and CCEPMG approaches use the long-run coefficients of MG and CCEMG

estimates, respectively, as initial values, and the Newton-Raphson algoithm. The Hausman test (p-values reported) is used to examine the null hypothesis of no difference

between the MG and PMG estimators, and between CCEMG and CCEPMG estimators. The asymptotic standard errors are reported in the brackets. For WG and CCEP

estimates the standard errors are corrected for possible heteroscedasticity in cross-sectional error variances. *, **, ${ }^{* * *}$ significant at $10 \%, 5 \%$ and $1 \%$, respectively. 
Table 6. Does Financial Development Cause Private Investment? 1970-1998

(Annual Data)

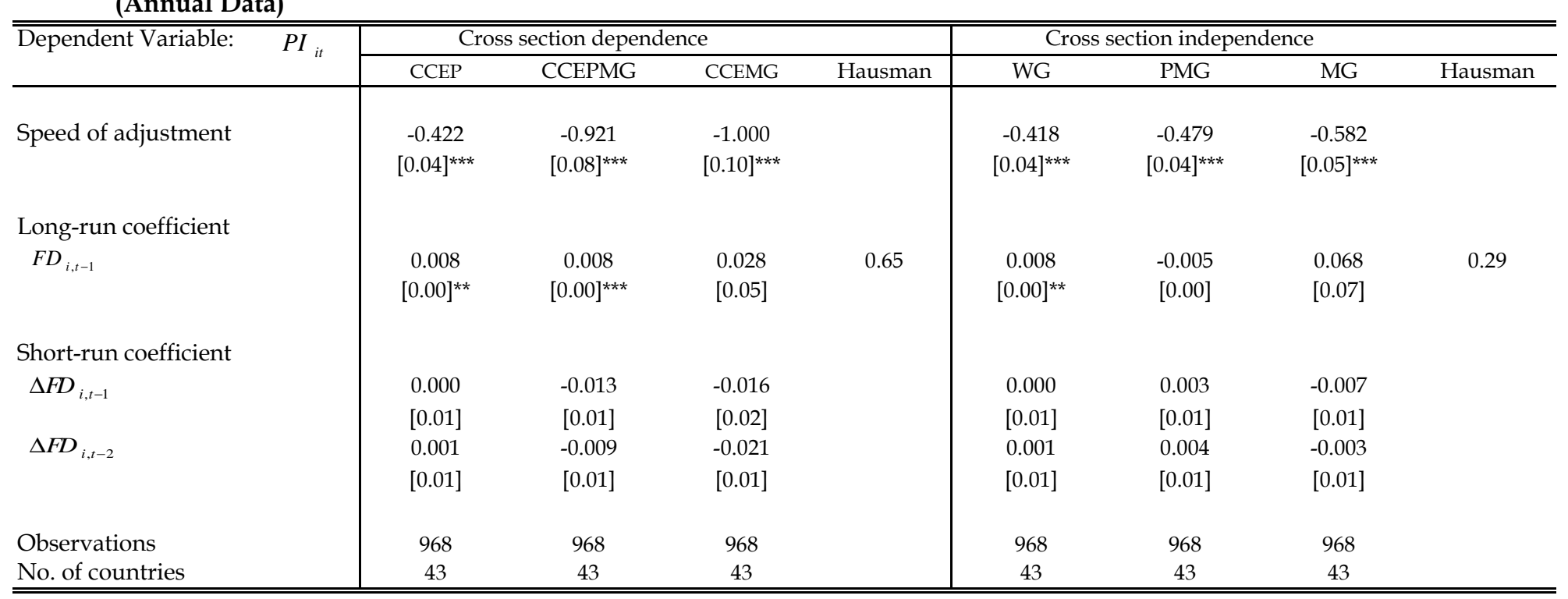

Note: See Table 5 for notes. 
the system GMM and WG approaches, ignoring the divergent performance across countries, are likely to produce misleading results. Moving from PMG to CCEPMG clearly highlights the importance of controlling for error dependence across countries.

The results from system GMM being in accordance with those from CCEPMG may stress the merit of system GMM for dynamic panels with a short time dimension, and the effectiveness of averaging data to eliminate the effects of common factors. However, for other economic applications the analyses on averaged data may not necessarily produce findings consistent with those on annual data. A note of caution may therefore be appropriate here: taking careful consideration over the integrated properties of the data, the error structure and the extent of heterogeneity is always worth keeping in mind in the econometric analysis of panel data.

In sum, after allowing for global interdependence and heterogeneity across countries, this analysis on annual data clearly shows positive long-run effects going in both directions between private investment and financial development. The findings in general suggest that surges of private investment stimulate the deepening of financial markets, and on the other hand, financial development facilitates resource mobilization, and increases the quantity of funds available for investment.

\section{Conclusion}

This paper aims to investigate the causality between aggregate private investment and financial development in a globalized world. Using a panel data set with 43 developing countries over 1970-98, the analysis is conducted in two steps. One is system GMM estimation on data for 5-year averages, indicating positive causal effects going in both directions and a high degree of persistence in the averaged data of private investment and financial development. The other is a common factor approach on annual data allowing for global interdependence and heterogeneity across countries. The analysis demonstrates that the series of both private investment and financial development are integrated, and two-way positive causal effects exist in the cointegrated system. In general, the paper implies that, in a glob- 
alised world, private investment is both an engine and a follower of financial development, and vice versa.

This analysis has produced significant insights into the interactions between two important aspects of economic activities, aggregate private investment and financial development, in developing countries. The implications of the findings can be summarised in the following:

First, the finding in terms of a positive effect of private investment on financial development has rich implications for the development of financial markets. Since sound macroeconomic policies, and a favorable economic and legal environment undoubtedly facilitate private investment, any efforts by government to reduce macroeconomic policy uncertainty, improve the regulatory framework and strengthen creditor and investor rights will be conducive to the development of financial markets. Moreover, the finding may shed light on a possible channel through which other variables drive financial development, for example, trade openness appears to promote financial development (Huang and Temple, 2005) and political liberalization brings about financial development (Huang, 2005).

Second, the finding on better financial development leading to a private investment boom has clear implications for the conduct of macroeconomic policies in developing countries. This paper suggests that as the financial system in a country becomes more sophisticated, more funds are channelled for productive investment so that firms find it easier to get access to funds. This finding is in support of the financial development framework proposed by McKinnon (1973) and Shaw (1973), who emphasize that financial liberalization and financial development can foster economic growth by boosting investment and its productivity, substantially influencing macroeconomic policies in developing countries since the 1970s. This research contributes to the existing body of research on the links between financial development and economic growth, by suggesting that financial development may enhance economic growth through a private investment boom.

Third, this research stresses the importance of taking careful account of error structure and heterogeneity in the econometric analysis of panel data. By considering the effects of common trends in a global economy and allowing for heterogeneity across countries, this analysis represents a 
significant improvement in comparison to existing research, which in general assumes error independence across countries. The results generated from existing research may deserve careful examination since the interactions and comovements of economic factors, and the trends of globalization, have been central features of the world economy in recent decades.

\section{References}

[1] Alonso-Borrego, C. and Arellano, M. (1999). 'Symmetrically normalised instrumental-variable estimation using panel data', Journal of Business Economic Statistics, vol. 17, pp. 36-49.

[2] Anderson, T. W. and Hsiao, C. (1981). 'Estimation of dynamic models with error components', Journal of the American Statistical Association, vol. 76, pp. 598-606.

[3] Anderson, T. W. and Hsiao, C. (1982). 'Formulation and estimation of dynamic models using panel data', Journal of Econometrics, vol. 18, pp. $47-82$.

[4] Arellano, M. and Bond, S. R. (1991). 'Some tests of specification for panel data: Monte carlo evidence and an application to employment equations', Review of Economic Studies, vol. 58, pp. 277-297.

[5] Arellano, M. and Bover, O. (1995). 'Another look at the instrumentalvariable estimation of error-components models', Journal of Econometrics, vol. 68, pp. 29-51.

[6] Bai, J. (2004). 'Estimating cross-section common stochastic trends in nonstationary panel data', Journal of Econometrics, vol. 122, pp. 13783.

[7] Bai, J. (2005). 'Panel data models with interactive fixed effects', http://www-cpr.maxwell.syr.edu/CampEconometrics/bai.pdf.

[8] Bai, J. and Ng, S. (2002). 'Determine the number of factors in approximate factor models', Econometrica, vol. 70, pp. 191-221. 
[9] Bai, J. and Ng, S. (2004). 'A PANIC attack on unit roots and cointegration', Econometrica, vol. 72, pp. 1127-1177.

[10] Banerjee, A., Marcellino, M. and Osbat, C. (2004). 'Some cautions on the use of panel methods for integrated series of macro-economic data', Econometrics Journal, vol. 7(2), pp. 322-340.

[11] Benhabib, J. and Spiegel, M. M. (2000). 'The financial development in growth and investment', Journal of Economic Growth, vol. 5, pp. 341-360.

[12] Bencivenga, V. R. and Smith, B. D. (1991). 'Financial intermediation and endogenous growth', Review of Economic Studies, vol. 58, pp. 195209.

[13] Bernanke, B. S. and Gertler, M. (1989). 'Agency costs, net wealth, and business fluctuations', American Economic Review, vol. 79, pp. 14-31.

[14] Bertola, G. and Caballero, R. J. (1994). 'Irreversibility and aggregate investment', Review of Economic Studies, vol. 61(2), pp. 223-46.

[15] Bond, S. (2002). 'Dynamic panel data models: a guide to micro data methods and practice', Portuguese Economic Journal, vol. 1, pp. 141162.

[16] Bond, S., Hoe- er, A. and Temple, J. (2001). 'GMM estimation of empirical growth models', CEPR discussion paper no. 3048.

[17] Bowsher, C. G. (2002). 'On testing overidentifying restrictions in dynamic panel data models', Economics Letters, vol. 77, pp. 211-220.

[18] Blundell, R. and Bond, S. (1998). 'Initial conditions and moment restrictions in dynamic panel data models', Journal of Econometrics, vol. 87, pp. 115-43.

[19] Blundell, R. and Bond, S. (2000). 'GMM estimation with persistent panel data: an application to production functions', Econometric Reviews, vol. 19, pp. 321-340. 
[20] Caballero, R. J. and Pindyck, R. S. (1996). "Uncertainty, investment" and industry evolution', International Economic Review, vol. 37(3), pp. 641-62.

[21] Caselli, F., Esquivel, G. and Lefort, F. (1996). 'Reopening the convergence debate: a new look at cross-country growth empirics', Journal of Economic Growth, vol. 1(3), pp. 363-90.

[22] Chamberlain, G. (1984). 'Panel data', Handbook of Econometrics, vol. 2, Chapter 22, pp. 1247-1318, Elsevier Science.

[23] Crafts, N. (2000). 'Globalization and growth in the twentieth century', IMF working paper no. 00/44.

[24] Demirgüç-Kunt, A. and Levine, R. (1996). 'Stock markets, corporate finance and economic growth: an overview', The Worldbank Economic Review, vol. 10(2), pp. 223-240.

[25] Demirgüç-Kunt, A. and Levine, R. (1999). 'Bank-based and marketbased financial systems: cross-country comparisons', The Worldbank Policy Research working paper no. 2143.

[26] Diamond, D. W. (1984). 'Financial intermediation and delegated monitoring', Review of Economic Studies, vol. 51, pp. 393-414.

[27] Diamond, D. W. and Dybvig, P. (1983). 'Bank runs, deposit insurance and liquidity', Journal of Political Economy, vol. 91(3), pp. 401-19.

[28] Dixit, A. (1989). 'Entry and exit decisions under uncertainty', Journal of Political Economy, vol. 97, pp. 620-38.

[29] Doms, M. and Dunne, T. (1998). 'Capital adjustment patterns in manufacturing plants', Review of Economic Dynamics, vol. 1, pp. 409-29.

[30] Engle, R. F. and Granger, C. W. J. (1987). 'Cointegration and error correction: representation, estimation and testing', Econometrica, vol. 55, pp. 251-76. 
[31] Frankel, J. A. and Rose, A. K. (1998). 'The endogeneity of the optimum currency area criteria', Economic Journal, vol. 108, pp. 1009-25.

[32] Gale, D. and Hellwig, M. (1985). 'Incentive-compatible debt contracts: The one-period problem', Review of Economic Studies, vol. 52, 647-64.

[33] Gengenbach, C., Palm, F. C. and Urbain, J. (2005). 'Panel cointegration testing in the presence of common factors', Maastricht Research School of Economics of Technology and Organization research paper no. 050.

[34] Greenwood, J. and Jovanovic, B. (1990). 'Financial development, growth, and the distribution of income', Journal of Political Economy, vol. 98 , pp. 1076-1107.

[35] Greenwood, J. and Smith, B. D. (1997). 'Financial markets in development, and the development of financial markets', Journal of Economic Dynamics and Control, vol. 21, pp. 145-181.

[36] Gregory, A. W., Head, A. C. and Raynauld, J. (1997). 'Measuring world business cycles', International Economic Review, vol. 38, pp. 677-701.

[37] Heston, A., Summers, R. and Aten, B. (2002). Penn World Table version 6.1, Center for International Comparisons at the University of Pennsylvania (CICUP).

[38] Holtz-Eakin, D., Newey, W. and Rosen, H. S. (1988). 'Estimation vector autoregressions with panel data', Econometrica, vol. 56(6), pp. 1371-95.

[39] Hsiao, C., Pesaran, M. H. and Tahmiscioglu, A. K. (2002). 'Maximum likelihood estimation of fixed effects dynamic panel data models covering short times periods', Journal of Econometrics, vol. 109, pp. 107-150.

[40] Huang, Y. (2005a). 'What determines financial development?' Bristol Economics Discussion Paper no 05/580.

[41] Huang, Y. (2005b). 'Will political liberalisation bring about financial development?' Bristol Economics Discussion Paper no. 05/578. 
[42] Huang, Y. and Temple, J. (2005). 'Does external trade promote financial development?' CEPR discussion paper no. 5150.

[43] Im, K., Pesaran, H. and Shin, Y. (2003). 'Testing for unit roots in heterogeneous panels', Journal of Econometrics, vol. 115, pp. 53-74.

[44] Imbs, J. (2003). 'Trade, finance, specialization and synchronization', IMF working paper no. 03/81.

[45] Islam, N. (1995). 'Growth empirics: A panel data approach', Quarterly Journal of Economics, vol. 110, pp. 1127-1170.

[46] King, R. and Levine, R. (1993). 'Finance and growth: Schumpeter might be right', Quarterly Journal of Economics, vol. 108 (3), pp. 717737.

[47] Kim, S. H., Kose, M. A. and Plummer, M. (2003). 'Dynamics of business cycle in Asia', Review of Development Economics, vol. 7, pp. 462-77.

[48] Kose, M. A., Prasad, E. S. and Terrones, M. E. (2003). 'Volatility and comovement in a globalized world economy: an empirical exploration', IMF working paper no. 03/246.

[49] Kose, M. A., Otrok, C. and Whiteman, C. H. (2003). 'International business cycles: world, region, and country-specific factors', American Economic Review, vol. 93, pp. 1216-39.

[50] Kruiniger, H. (2002). 'On the estimation of panel regression models with fixed effects', Queen Mary Economics working paper wp450, University of London.

[51] Leahy, J. (1993). 'Investment in competitive equilibrium: the optimality of myopic behaviour', Quarterly Journal of Economics, vol. 108, pp. 1105-1133.

[52] Levin, A., Lin, F. and Chu, C. (2002). 'Unit root tests in panel data: asymptotic and finite-sample properties', Journal of Econometrics, vol. 108, pp. 1-24.. 
[53] Levine, R., Loayza, N. and Beck, T. (2000). 'Financial intermediation and growth: causality and causes', Journal of Monetary Economics, vol. 46(1), pp. 31-77.

[54] Levine, R. and Renelt, D. (1992). 'A sensitivity analysis of cross-country growth regressions', American Economic Review, vol. 82, pp. 942-63.

[55] Maddala, G. S. and Wu, S. (1999). 'A comparative study of unit root tests with panel data and a new simple test', Oxford Bulletin of Economics and Statistics, vol. 61, pp. 631-652.

[56] Mankiw, N. G., Romer, D. and Weil, D. N. (1992). 'A contribution to the empirics of economic growth', Quarterly Journal of Economics, vol. 107, pp. 407-437.

[57] McKinnon, R. I. (1973) Money and Capital in Economic Development, Washington D.C. Brookings Institution.

[58] Moon, H. R. and Perron, B. (2004). 'Testing for a unit root in panels with dynamic factors', Journal of Econometrics, vol. 122, pp. 81-126.

[59] Ndikumana, L. (2000). 'Financial determinants of domestic investment in Sub-Saharan Africa: evidence from panel data', World Development, vol. 28(2), pp. 381-400.

[60] Ndikumana, L. (2005). 'Financial development, financial structure, and domestic investment: interanatioal evidence', Journal of International Money and Finance, vol. 24, pp. 651-73.

[61] Nickel, S. J. (1981) 'Biases in dynamic models with fixed effects', Econometrica, vol. 49, pp. 1417-1426.

[62] Papke, L. E. and Wooldridge, J. M. (2005). 'A computational trick for delta-method standard errors', Economic Letters, vol. 86, pp. 413-17.

[63] Pedroni, P. (1999). 'Critical values for cointegration tests in heterogeneous panels with multiple regressors', Oxford Bulletin of Economics and Statistics, vol. 61, pp. 653-670. 
[64] Pedroni, P. (2004). 'Panel cointegration, asymptotic and finite sample properties of pooled time series tests with an application to the PPP hypothesis', Econometric Theory, vol. 20, pp. 597-625.

[65] Pesaran, M. H. (2006a). 'Estimation and inference in large heterogeneous panels with a multifactor error structure', Econometrica, forthcoming.

[66] Pesaran, M. H. (2006b). 'A simple panel unit root test in the presence of cross section dependence', Cambridge University DAE working paper no. 0346 .

[67] Pesaran, M. H. and Smith, R. P. (1995). 'Estimating long-run relationships from dynamic heterogeneous panels', Journal of Econometrics, vol. 68 , pp. 79-113.

[68] Pesaran, M. H., Shin, Y. and Smith, R. P. (1999). 'Pooled mean group estimation of dynamic heterogeneous panels', Journal of American Statistical Association, vol. 94, pp. 621-34.

[69] Schich, S. and Pelgrin, F. (2002). 'Financial development and investment: panel data evidence for OECD countries from 1970-1997', Applied Economics Letters, vol. 9, pp. 1-7.

[70] Shaw, E. S. (1973). Financial Deepening in Economic Development, New York, Oxford University Press.

[71] Townsend, R. M. (1979). 'Optimal contracts and competitive markets with costly state verification', Journal of Economic theory, vol. 21, pp. 265-93.

[72] Windmeijer, F. (2005). 'A finite sample correction for the variance of linear efficient two-step GMM estimators', Journal of Econometrics, vol. 126(1), pp. 25-51.

[73] Williamson, S. D. (1986). 'Costly monitoring, financial intermediation, and equilibrium credit rationing', Journal of Monetary Economics, vol. 18, pp. 159-79. 
[74] Williamson, S. D. (1987). 'Costly monitoring, loan contracts, and equilibrium credit rationing', Quarterly Journal of Economics, vol. 102, pp. 135-45.

[75] World Bank. Financial Development and Structure Database (2005).

[76] World Bank. Global Development Network (2002). 


\section{Appendix Figure 1. Time Series of Common Factors for FD and PI}

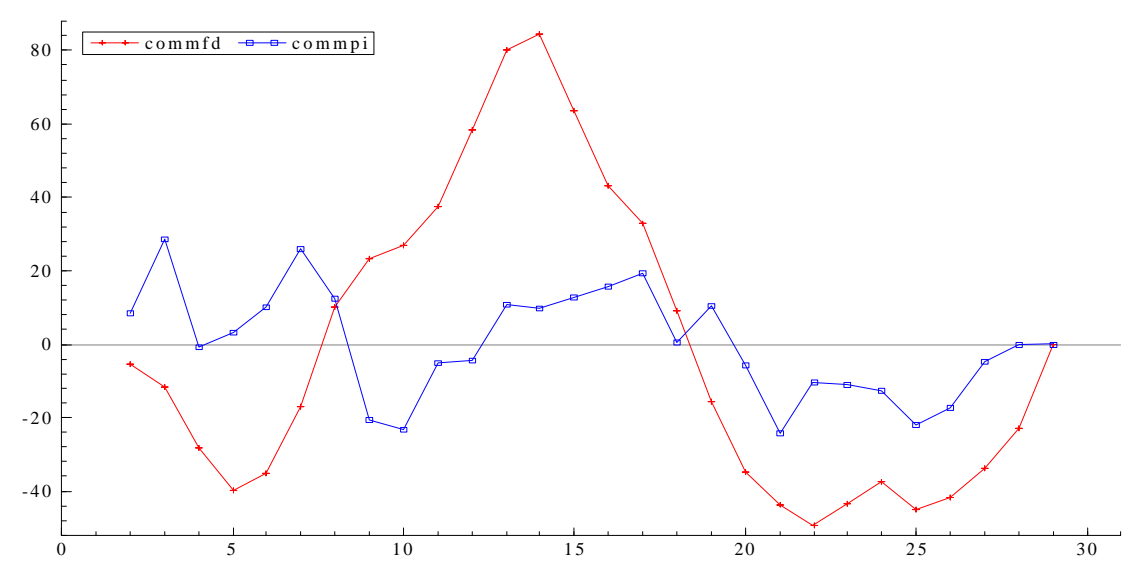

Note: This graph depicts the time series of common factors for FD and PI, identified by using the PANIC approach due to Bai and Ng (2004), over 28 years (1971-98). Here commfd denotes the common factor for the series of FD, while commpi denotes the common factor for the series of PI.

\section{Appendix Table 1. The variables}

\begin{tabular}{|c|c|c|}
\hline Variable & Description & Source \\
\hline FD & $\begin{array}{l}\text { Index for financial development in this paper, mainly } \\
\text { measuring the size of financial intermediary } \\
\text { developmnet. It is the first principal component of } \\
\text { LLY, PRIVO and BTOT. }\end{array}$ & \\
\hline LLY & $\begin{array}{l}\text { Liquid Liabilities, the ratio of liquid liabilities of } \\
\text { financial system (currency plus demand and interest- } \\
\text { bearing liabilities of banks and nonbanks) to GDP. }\end{array}$ & $\begin{array}{l}\text { Financial Development and } \\
\text { Structure Database (FDS) in } \\
\text { World Bank, } 2005\end{array}$ \\
\hline PRIVO & $\begin{array}{l}\text { Private Credit, the ratio of credits issued to private } \\
\text { sector by banks and other financial intermediaries to } \\
\text { GDP. }\end{array}$ & FDS, 2005 \\
\hline ВТОТ & $\begin{array}{l}\text { Commercial-central Bank, the ratio of commercial } \\
\text { bank assets to the sum of commercial bank and } \\
\text { central bank assets. }\end{array}$ & FDS, 2005 \\
\hline PI & $\begin{array}{l}\text { The ratio of nominal private investment to nominal } \\
\text { GDP. It is replaced by PI/ } 100 \text {. }\end{array}$ & $\begin{array}{l}\text { Global Development } \\
\text { Network (GDN), } 2002\end{array}$ \\
\hline LGDP & Real GDP per capita (Chain) in log. & Penn World Table 6.1 \\
\hline OPENC & $\begin{array}{l}\text { The sum of exports and imports over GDP (at current } \\
\text { prices). It is replaced by } \log (1+\text { OPENC/100). }\end{array}$ & \\
\hline
\end{tabular}


Appendix Table 2. Descriptive Statistics

\begin{tabular}{|c|c|c|c|c|c|c|}
\hline \multirow{2}{*}{$\begin{array}{l}\text { Variable } \\
\text { FD }\end{array}$} & \multirow{4}{*}{$\begin{array}{l}\text { overall } \\
\text { between } \\
\text { within }\end{array}$} & \multirow{2}{*}{$\frac{\text { Mean }}{-0.52}$} & \multirow{2}{*}{$\begin{array}{r}\text { Std. Dev. } \\
0.91\end{array}$} & \multirow{2}{*}{$\frac{\text { Min }}{-2.65}$} & \multicolumn{2}{|c|}{ Max Observations } \\
\hline & & & & & 4.14 & $\mathrm{~N}=1198$ \\
\hline & & & 0.75 & -2.13 & 1.66 & $n=43$ \\
\hline & & & 0.52 & -2.36 & 2.34 & $\mathrm{~T}-\mathrm{bar}=27.86$ \\
\hline \multirow[t]{3}{*}{ PI } & overall & 0.14 & 0.07 & 0.00 & 0.42 & $\mathrm{~N}=1183$ \\
\hline & between & & 0.05 & 0.02 & 0.25 & $\mathrm{n}=43$ \\
\hline & within & & 0.04 & 0.00 & 0.42 & $\mathrm{~T}-\mathrm{bar}=27.51$ \\
\hline \multirow[t]{3}{*}{ LGDP } & overall & 3.47 & 0.35 & 2.76 & 4.19 & $\mathrm{~N}=1183$ \\
\hline & between & & 0.34 & 2.88 & 4.02 & $n=43$ \\
\hline & within & & 0.09 & 3.09 & 3.82 & T-bar $=29$ \\
\hline \multirow[t]{3}{*}{ OPENC } & overall & 0.57 & 0.29 & 0.06 & 2.09 & $\mathrm{~N}=1247$ \\
\hline & between & & 0.26 & 0.16 & 1.23 & $\mathrm{n}=43$ \\
\hline & within & & 0.14 & 0.04 & 1.43 & T-bar $=29$ \\
\hline
\end{tabular}

Note: Appendix Table 1 describes all variables in detail.

\section{Appendix Table 3: The List of Countries in the Full Sample}

\begin{tabular}{|c|c|c|c|c|c|}
\hline \multicolumn{2}{|c|}{ East Asia \& Pacific } & \multicolumn{2}{|c|}{ Sub Sahara Africa } & \multicolumn{2}{|c|}{ Latin America \& Caribbean } \\
\hline PHL & Philippines & GAB & Gabon & HND & Honduras \\
\hline MYS & Malaysia & SEN & Senegal & TTO & Trinidad and Tobago \\
\hline PNG & Papua New Guinea & NGA & Nigeria & GTM & Guatemala \\
\hline THA & Thailand & NER & Niger & CRI & Costa Rica \\
\hline \multirow[t]{2}{*}{ KOR } & Korea, Rep. & MUS & Mauritius & HTI & Haiti \\
\hline & & KEN & Kenya & SLV & El Salvador \\
\hline \multicolumn{2}{|c|}{ South Asia } & TGO & Togo & BRB & Barbados \\
\hline IND & India & MDG & Madagascar & COL & Colombia \\
\hline NPL & Nepal & GHA & Ghana & PER & Peru \\
\hline \multirow[t]{2}{*}{ PAK } & Pakistan & GMB & Gambia, The & VEN & Venezuela \\
\hline & & RWA & Rwanda & ECU & Ecuador \\
\hline \multicolumn{2}{|c|}{ Middle East \& North Africa } & CMR & Cameroon & MEX & Mexico \\
\hline DZA & Algeria & CIV & Cote d'Ivoire & ARG & Argentina \\
\hline MAR & Morocco & BDI & Burundi & URY & Uruguay \\
\hline \multirow[t]{3}{*}{ EGY } & Egypt, Arab Rep. & $\mathrm{ZAF}$ & South Africa & $\mathrm{CHL}$ & Chile \\
\hline & & & & DOM & Dominican Republic \\
\hline & & & & PRY & Paraguay \\
\hline
\end{tabular}


Appendix Table 4. Robustness Test - GDP in log Included

(5-year-average Data)

A. Does Private Investment Cause Financial Development? 1970-1998

\begin{tabular}{|c|c|c|c|c|c|}
\hline 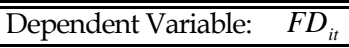 & OLS & WG & SYS-GMM & SYS-GMM-1 & SYS-GMM-2 \\
\hline \multirow[t]{2}{*}{$F D_{i, t-1}$} & 0.879 & 0.427 & 0.753 & 0.638 & 0.693 \\
\hline & {$[15.21]^{* * *}$} & {$[5.46]^{\star * *}$} & {$[6.38]^{\star * *}$} & {$[6.14]^{\star * *}$} & {$[3.78]^{* * *}$} \\
\hline \multirow[t]{2}{*}{$P I_{i, t-1}$} & 2.744 & 3.845 & 5.692 & 6.007 & 4.679 \\
\hline & {$[4.17]^{\star \star *}$} & {$[4.25]^{\star \star *}$} & {$[6.70]^{\star * *}$} & {$[4.65]^{\star * *}$} & {$[3.13]^{\star \star *}$} \\
\hline \multirow[t]{2}{*}{$L G D P_{i t}$} & 0.014 & 2.215 & 0.634 & 0.972 & 1.240 \\
\hline & {$[0.12]$} & {$[4.41]^{\star \star \star}$} & [1.30] & {$[1.73]^{*}$} & {$[2.11]^{\star *}$} \\
\hline M1 (p-value) & & & 0.00 & 0.00 & 0.02 \\
\hline M2 (p-value) & & & 0.99 & 0.80 & 0.46 \\
\hline Sargan (p-value) & & & 0.51 & 0.35 & 0.30 \\
\hline Diff-Sargan (p-value) & & & 0.98 & 1.00 & 0.71 \\
\hline Granger Causality ( $p$-value) & 0.00 & 0.00 & 0.00 & 0.00 & 0.00 \\
\hline LR effect point estimate & 22.61 & 6.71 & 23.04 & 16.58 & 18.26 \\
\hline (Standard error) & {$[11.89]^{*}$} & {$[1.81]^{\star * *}$} & {$[10.81]^{\star *}$} & {$[5.41]^{\star * *}$} & [11.57] \\
\hline Observations & 212 & 212 & 212 & 212 & 212 \\
\hline
\end{tabular}

B. Does Financial Development Cause Private Investment? 1970-1998

\begin{tabular}{|c|c|c|c|c|c|}
\hline Dependent Variable: $\quad P I_{i t}$ & OLS & WG & SYS-GMM & SYS-GMM-1 & SYS-GMM-2 \\
\hline \multirow[t]{2}{*}{$P I_{i, t-1}$} & 0.698 & 0.186 & 0.512 & 0.498 & 0.352 \\
\hline & {$[10.95]^{\star \star *}$} & {$[2.39]^{* *}$} & {$[5.19]^{\star * *}$} & {$[5.01]^{\star * \star}$} & {$[3.28]^{\star * *}$} \\
\hline \multirow{2}{*}{$F D_{i, t-1}$} & 0.007 & 0.004 & 0.004 & -0.013 & 0.012 \\
\hline & {$[1.74]^{*}$} & {$[0.55]$} & {$[0.54]$} & {$[1.36]$} & [1.43] \\
\hline \multirow[t]{2}{*}{$L G D P_{i t}$} & 0.016 & 0.081 & 0.092 & 0.095 & 0.103 \\
\hline & {$[1.60]$} & {$[1.88]^{*}$} & {$[3.34]^{\star * *}$} & [1.19] & {$[3.08]^{\star * *}$} \\
\hline M1 (p-value) & & & 0.00 & 0.00 & 0.01 \\
\hline M2 (p-value) & & & 0.40 & 0.47 & 0.26 \\
\hline Sargan (p-value) & & & 0.45 & 0.27 & 0.46 \\
\hline Diff-Sargan (p-value) & & & 0.88 & 0.67 & 0.97 \\
\hline Granger Causality (p-value) & 0.08 & 0.58 & 0.59 & 0.18 & 0.16 \\
\hline LR effect point estimate & 0.02 & 0.00 & 0.01 & -0.03 & 0.02 \\
\hline (Standard error) & {$[0.01]^{*}$} & {$[0.01]$} & {$[0.01]$} & {$[0.02]$} & {$[0.01]$} \\
\hline Observations & 198 & 198 & 198 & 198 & 198 \\
\hline
\end{tabular}

Notes: Log GDP is included in the models to test the robustness of the findings of Tables 1 and 2 . See Table 1 for more notes. 


\section{Appendix Table 5. Robustness Test -- OPENC lncluded (5-year-average Data)}

\begin{tabular}{|c|c|c|c|c|c|}
\hline 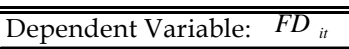 & OLS & $\overline{\text { WG }}$ & $\overline{\text { SYS-GMM }}$ & $\begin{array}{l}\text { SYS-GMM-1 } \\
\end{array}$ & 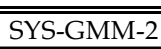 \\
\hline$F D_{i, t-1}$ & $\begin{array}{l}0.863 \\
{[15.15]^{\star * *}}\end{array}$ & $\begin{array}{l}0.565 \\
{[7.86]^{* * *}}\end{array}$ & $\begin{array}{l}0.734 \\
{[8.31]^{\star \star \star}}\end{array}$ & $\begin{array}{l}0.764 \\
{[6.78]^{* * *}}\end{array}$ & $\begin{array}{l}0.478 \\
{[3.22]^{\star * \star}}\end{array}$ \\
\hline$P I_{i, t-1}$ & $\begin{array}{l}2.699 \\
{[4.85]^{* * *}}\end{array}$ & 4.206 & $\begin{array}{l}4.759 \\
{[3.09]^{* * *}}\end{array}$ & 7.494 & 2.713 \\
\hline OPENC it & 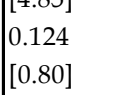 & $\begin{array}{l}{[2.00]} \\
0.746 \\
{[2.41]^{* *}}\end{array}$ & $\begin{array}{l}0.603 \\
{[1.28]}\end{array}$ & $\begin{array}{l}{[.21]} \\
-0.143 \\
{[0.23]}\end{array}$ & $\begin{array}{l}1.305 \\
{[3.50]^{* * *}}\end{array}$ \\
\hline M1 (p-value) & & & 0.01 & 0.00 & 0.06 \\
\hline M2 (p-value) & & & 0.92 & 0.90 & 0.90 \\
\hline Sargan (p-value) & & & 0.32 & 0.25 & 0.36 \\
\hline Diff-Sargan (p-value) & & & 0.25 & 0.09 & 0.30 \\
\hline Granger Causality (p-value) & 0.00 & 0.00 & 0.00 & 0.00 & 0.06 \\
\hline LR effect point estimate & 19.67 & 9.68 & 17.88 & 31.74 & 5.20 \\
\hline (Standard error) & {$[7.87]^{* *}$} & {$[2.59]^{* * *}$} & {$[8.47]^{* *}$} & {$[14.33]^{* *}$} & {$[3.73]$} \\
\hline Observations & 212 & 212 & 212 & 212 & 212 \\
\hline
\end{tabular}

B. Does Financial Development Cause Private Investment? 1970-1998

\begin{tabular}{|c|c|c|c|c|c|}
\hline $\begin{array}{l}\text { Dependent Variable: } \quad P I_{i t} \\
\end{array}$ & OLS & WG & SYS-GMM & SYS-GMM-1 & SYS-GMM-2 \\
\hline \multirow[t]{2}{*}{$P I_{i, t-1}$} & 0.742 & 0.228 & 0.455 & 0.340 & 0.305 \\
\hline & {$[13.87]^{\star * *}$} & {$[2.82]^{* * *}$} & {$[3.61]^{\star * *}$} & {$[2.24]^{* *}$} & {$[2.38]^{* *}$} \\
\hline \multirow[t]{2}{*}{$F D_{i, t-1}$} & 0.008 & 0.010 & 0.013 & -0.010 & 0.019 \\
\hline & {$[1.80]^{*}$} & [1.60] & {$[1.75]^{*}$} & {$[0.80]$} & {$[2.13]^{* *}$} \\
\hline \multirow[t]{2}{*}{$O P E N C_{i t}$} & 0.002 & 0.004 & 0.018 & 0.071 & 0.029 \\
\hline & {$[0.15]$} & {$[0.14]$} & {$[0.55]$} & {$[1.00]$} & {$[0.83]$} \\
\hline M1 (p-value) & & & 0.01 & 0.01 & 0.02 \\
\hline M2 (p-value) & & & 0.33 & 0.39 & 0.21 \\
\hline Sargan (p-value) & & & 0.24 & 0.36 & 0.15 \\
\hline Diff-Sargan (p-value) & & & 0.10 & 0.13 & 0.03 \\
\hline Granger Causality (p-value) & 0.07 & 0.11 & 0.09 & 0.43 & 0.04 \\
\hline LR effect point estimate & 0.03 & 0.01 & 0.02 & -0.01 & 0.03 \\
\hline (Standard error) & {$[0.02]^{*}$} & {$[0.01]$} & {$[0.01]^{*}$} & {$[0.02]$} & {$[0.01]^{\star *}$} \\
\hline Observations & 198 & 198 & 198 & 198 & 198 \\
\hline
\end{tabular}

Notes: Trade openness (OPENC) is included in the models to test the robustness of the findings of Tables 1 and 2. See Table 1 for more notes. 
Appendix Table 6. Robustness Test -- 2 lags (5-year-average Data)

A. Does Private Investment Cause Financial Development? 1970-1998

\begin{tabular}{|c|c|c|c|c|c|}
\hline Dependent Variable: $\quad F D_{i t}$ & OLS & WG & SYS-GMM & SYS-GMM-1 & SYS-GMM-2 \\
\hline \multirow[t]{2}{*}{$F D_{i, t-1}$} & 1.076 & 0.492 & 0.683 & 0.564 & 0.383 \\
\hline & {$[10.18]^{* * *}$} & {$[5.07]^{* * *}$} & {$[4.46]^{* * *}$} & {$[2.95]^{* * *}$} & [1.36] \\
\hline \multirow[t]{2}{*}{$F D_{i, t-2}$} & -0.194 & -0.179 & -0.216 & -0.174 & -0.079 \\
\hline & {$[1.67]^{*}$} & {$[1.94]^{*}$} & {$[1.54]$} & [1.17] & {$[0.67]$} \\
\hline \multirow[t]{2}{*}{$P I_{i, t-1}$} & 3.647 & 4.767 & 5.735 & 7.524 & 5.605 \\
\hline & {$[3.75]^{* * *}$} & {$[4.20]^{* * *}$} & {$[2.85]^{* * *}$} & {$[2.87]^{* * *}$} & {$[2.88]^{* * *}$} \\
\hline \multirow[t]{2}{*}{$P I_{i, t-2}$} & -1.118 & 3.385 & 3.305 & 3.983 & 2.812 \\
\hline & {$[1.00]$} & {$[2.88]^{* * *}$} & {$[1.88]^{*}$} & {$[2.55]^{* *}$} & {$[1.76]^{*}$} \\
\hline M1 (p-value) & & & 0.02 & 0.09 & 0.37 \\
\hline M2 (p-value) & & & 0.53 & 0.84 & 0.77 \\
\hline Sargan (p-value) & & & 0.21 & 0.16 & 0.23 \\
\hline Diff-Sargan (p-value) & & & 0.64 & 0.60 & 0.88 \\
\hline Granger Causality (p-value) & 0.00 & 0.00 & 0.00 & 0.00 & 0.01 \\
\hline LR effect point estimate & 21.5 & 11.87 & 16.96 & 18.89 & 12.09 \\
\hline (Standard error) & {$[11.94]^{*}$} & {$[2.48]^{* * *}$} & {$[6.36]^{* *}$} & {$[5.79]^{* * *}$} & {$[5.52]^{* *}$} \\
\hline Observations & 169 & 169 & 169 & 169 & 169 \\
\hline
\end{tabular}

B. Does Financial Development Cause Private Investment? 1970-1998

\begin{tabular}{l|lllll}
\hline \hline Dependent Variable: $P I_{i t}$ & OLS & WG & SYS-GMM & SYS-GMM-1 & SYS-GMM-2 \\
\hline$P I_{i, t-1}$ & 0.692 & 0.087 & 0.506 & 0.565 & 0.402 \\
& {$[8.34]^{* * *}$} & {$[0.99]$} & {$[4.24]^{* * *}$} & {$[3.88]^{* * *}$} & {$[2.82]^{* * *}$} \\
$P I_{i, t-2}$ & 0.086 & -0.081 & -0.090 & -0.038 & -0.064 \\
& {$[0.99]$} & {$[0.93]$} & {$[0.84]$} & {$[0.34]$} & {$[0.64]$} \\
$F D_{i, t-1}$ & 0.010 & 0.016 & 0.022 & -0.003 & 0.027 \\
$F D_{i, t-2}$ & {$[1.30]$} & {$[2.09]^{* *}$} & {$[1.96]^{*}$} & {$[0.25]$} & {$[2.08]^{* *}$} \\
& -0.004 & 0.002 & -0.005 & -0.002 & -0.004 \\
& {$[0.50]$} & {$[0.28]$} & {$[0.81]$} & {$[0.25]$} & {$[0.58]$} \\
M1 (p-value) & & & & & 0.05 \\
M2 (p-value) & & & 0.03 & 0.16 & 0.08 \\
Sargan (p-value) & & & 0.14 & 0.47 & 0.45 \\
Diff-Sargan (p-value) & & & 0.61 & 0.27 & 0.25 \\
Granger Causality (p-value) & 0.20 & 0.03 & 0.09 & 0.73 & 0.10 \\
LR effect point estimate & 0.03 & 0.02 & 0.03 & -0.01 & 0.03 \\
(Standard error) & {$[0.02]$} & {$[0.01]^{* *}$} & {$[0.01]^{* *}$} & {$[0.03]$} & {$[0.01]^{* *}$} \\
Observations & 155 & 155 & 155 & 155 & 155 \\
\hline \hline
\end{tabular}

Notes: AR(2) models are considered to test the robustness of the findings of Tables 1 and 2. See Table 1 for more notes. 
Appendix Table 7. Determination of the Numbers of Common Factors for FD and PI

\begin{tabular}{lll}
\hline \hline & FD & PI \\
\hline $\mathrm{r}=1$ & 2.654 & 3.339 \\
$\mathrm{r}=2$ & 3.000 & 3.626 \\
$\mathrm{r}=3$ & 3.202 & 3.823 \\
$\mathrm{r}=4$ & 3.373 & 4.005 \\
$\mathrm{r}=5$ & 3.539 & 4.183 \\
$\mathrm{r}=6$ & 3.703 & 4.355 \\
$\mathrm{r}=7$ & 3.866 & 4.522 \\
$\mathrm{r}=8$ & 4.030 & 4.687 \\
\hline \hline
\end{tabular}

Note: This table reports the values of Information Criteria (IC1) (Bai and $\mathrm{Ng}$, 2002) for different numbers of factors ( $\mathrm{r}$ ).

The integer minimizing a criterion function, IC1 for example, is the estimated number of factors. 